\title{
Curso de Ciências Moleculares: uma singularidade nas colmeias
}

\author{
Molecular Science Course: a singularity in the campus
}

\author{
A. F. R. de Toledo Piza* \\ Instituto de Física, Universidade de São Paulo, São Paulo, SP, Brasil
}

Recebido em 13 de Dezembro, 2016. Aceito em 19 de Dezembro, 2016.

\begin{abstract}
As circunstâncias e motivações ligadas à criação do Curso Experimental de Ciências Moleculares em 1991 na Universidade de São Paulo são reconstruídas com base em testemunhos publicados de seus criadores e consideradas com relação aos sucessos e dificuldades havidas ao longo do amadurecimento do curso.
\end{abstract}

Palavras-chave: Ciências Moleculares, Curso Experimental, Multidisciplinaridade

The circumstances and motivations leading to the creation in 1991 of the "Curso Experimental de Ciências Moleculares" (Molecular Science Experimental Course) at the University of São Paulo are reconstructed on the base of published testimonies of its creators. They are then considered in view of the successes and difficulties which were met along the maturing of the course.

Keywords: Molecular Science, Experimental Course, Multidisciplinarity

(...) Al abrir los ojos, vi el Aleph.

-¿El Aleph? - repetí.

- Sí, el lugar donde están, sin confundirse, todos los lugares del orbe, vistos desde todos los ángulos.

Jorge Luis Borges, El Aleph, Emecé Editores, S.A., Buenos Aires 1957

\section{Introdução}

No início do segundo semestre letivo deste ano de 2016, o Curso de Ciências Moleculares (CCM) da Universidade de São Paulo, vinculado diretamente à pró-reitoria de graduação, e nesse sentido mantendo independência das diferentes unidades universitárias embora contando com a colaboração de várias delas para seu funcionamento, levou a cabo o processo seletivo para sua vigésima sexta turma. Como no caso da primeira turma, cujo processo seletivo foi levado a cabo no início do segundo semestre letivo de 1991, os candidatos eram estudantes aprovados em vestibular e matriculados em outros cursos da universidade. Os aprovados, também como no caso da primeira turma, receberam a opção de matrícula no CCM, mantida sua vaga na unidade de origem

*Endereço de correspondência: piza@if.usp.br. como garantia da possibilidade de retorno à opção original em caso de desistência ou graduação pelo novo curso.

Se, como assim se constata, o funcionamento do CCM acaba de ultrapassar o marco de seu jubileu de prata, isso não significa tantos anos de mar calmo e viagem tranquila. Em particular, por um período de cerca de dois anos a partir do seu quarto ano de funcionamento, uma situação de crise teve que ser controlada através de uma série de ajustes do plano inicial, que acabaram por levar o curso essencialmente à sua estrutura atual já em fins de 1995. Pouco posterior (meados de 1996) é a 'oficialização' do CCM através do seu reconhecimento pelos órgãos próprios externos à universidade. $\mathrm{O}$ funcionamento do curso tem se mantido, a partir de então, em um regime (quase) estacionário por um tempo que chega agora a duas décadas. 
A estabilidade assim exposta indica a existência de um nicho ecológico, no âmbito da universidade, para um curso dessa natureza. Essa mesma estabilidade, por outro lado, é algumas vezes sentida como uma limitação, por não indicar o crescimento em escala muitas vezes tido como condicionante para diagnósticos de sucesso. Pois bem, não pode haver dúvida sobre o fato de que o CCM, na escala em que tem operado, tem sido bastante produtivo, no sentido de ter formado regularmente estudantes com a melhor formação básica de natureza multidisciplinar, e que puderam se beneficiar das melhores condições, disponíveis na universidade como um todo, para sua formação complementar em vista de uma carreira de pesquisa nas ciências da natureza e em matemática. Quanto a questões de crescimento, deve-se ter em conta que a escalabilidade da inovação representada pelo curso deve ser considerada não necessária e exclusivamente em termos de seu próprio tamanho, mas também tendo em conta e vista a possível disseminação de várias de suas características particulares para outros domínios da universidade.

O propósito central deste texto é tratar de por em evidência, através de um relato exposto de forma essncialmente cronológica, o processo de adaptação do curso à universidade, sendo esta o meio em que ele se insere. A meu ver, esse processo teve um de seus momentos cruciais na crise dos quatro anos. Paralelamente a isso, o funcionamento do curso pode ter oferecido idéias e oportunidades de aperfeiçoamente à própria universidade como um todo, algumas das quais tendo até sido efetivamente implementadas. Há no texto referências a fatos como também várias interpretações. Procurei ser tanto quanto possível objetivo quanto aos fatos, sendo no entanto evidentemente o único responsável pelas interpretações. O leitor saberá distinguir uns de outras.

Começando por caracterizar, na seção 2, o contexto geral da Universidade de São Paulo a partir de sua constituição em 1934, as ideias e o processo que levou à instituição do então chamado Curso Experimental de Ciências Moleculares a partir de 1990, ano do início da gestão de Roberto Lobo na reitoria da universidade, bem como os primeiros resultados e dificuldades dessa iniciativa, são tratados nas seções 3 e 4 . As seções 5 e 6 tratam respectivamente da transição para o regime que tem prevalecido durante os últimos anos e das características e vulnerabilidades desse regime. Finalmente, na seção 7 são apresentadas algumas ideias sobre a possível relevância da experiência representada pelo funcionamento do Curso de Ciências Moleculares para outros setores da universidade.

\section{Contexto}

O processo de criação da Universidade de São Paulo, no ano de 1934, consistiu em uma aglutinação de escolas preexistentes de 'ensino superior', pensada como eventualmente estabilizada pela criação de uma faculdade adicional, a Faculdade de Filosofia, Ciências e Letras. De acordo com a concepção dos criadores, esta nova Faculdade receberia das escolas aglutinadas as cátedras que fossem de relevância básica comum, passaria a ministrar as respectivas disciplinas para as diferentes escolas, e dedicar-se-ia à pesquisa fundamental em cada uma das diferentes áreas de seu amplo espectro temático [1]. Além disso, caberia a ela a formação de professores para o ensino secundário e superior, o que implicou na criação de cursos nas suas áreas de atuação, sem qualquer vinculação com as antigas escolas. Surgiram assim, desde o início, cursos superiores nas áreas básicas de filosofia, ciências (incluindo matemática, física, química, geologia e biologia, história e geografia, ciências sociais e políticas) e letras $[2$.

É um fato notório que o projeto integrador envolvendo a Faculdade de Filosofia, Ciências e Letras não prosperou em sua totalidade, tendo mesmo, por isso, sido de certa forma retomado muito depois, na reforma universitária instituída pela lei 5.540 de 28 de novembro de 1968 (portanto cerca de duas semanas antes do AI5). No entanto, é preciso mencionar que há, nos primeiros tempos da universidade, pelo menos um caso de clara aderência ao projeto integrador: tanto em 1934 como em 1935, as disciplinas básicas de física foram ministradas também para os alunos da Escola Politécnica pelo professor Gleb Wataghin, trazido da Europa para integrar o corpo docente do Departamento de Física da Faculdade de Filosofia, Ciências e Letras (v. fig. 1).

A implantação na USP da reforma universitária de 1968 se deu através da elaboração de um novo regimento, em 1969. Ela modificava a forma original do mecanismo integrador ao abolir o regime de cátedras, substituindo-as por Departamentos. Estes foram efetivamente incorporados no novo estatuto como as "menores frações da estrutura universitária para os efeitos de organização didático-científica e administrativa" [3]. Esta medida efetivamente am- 


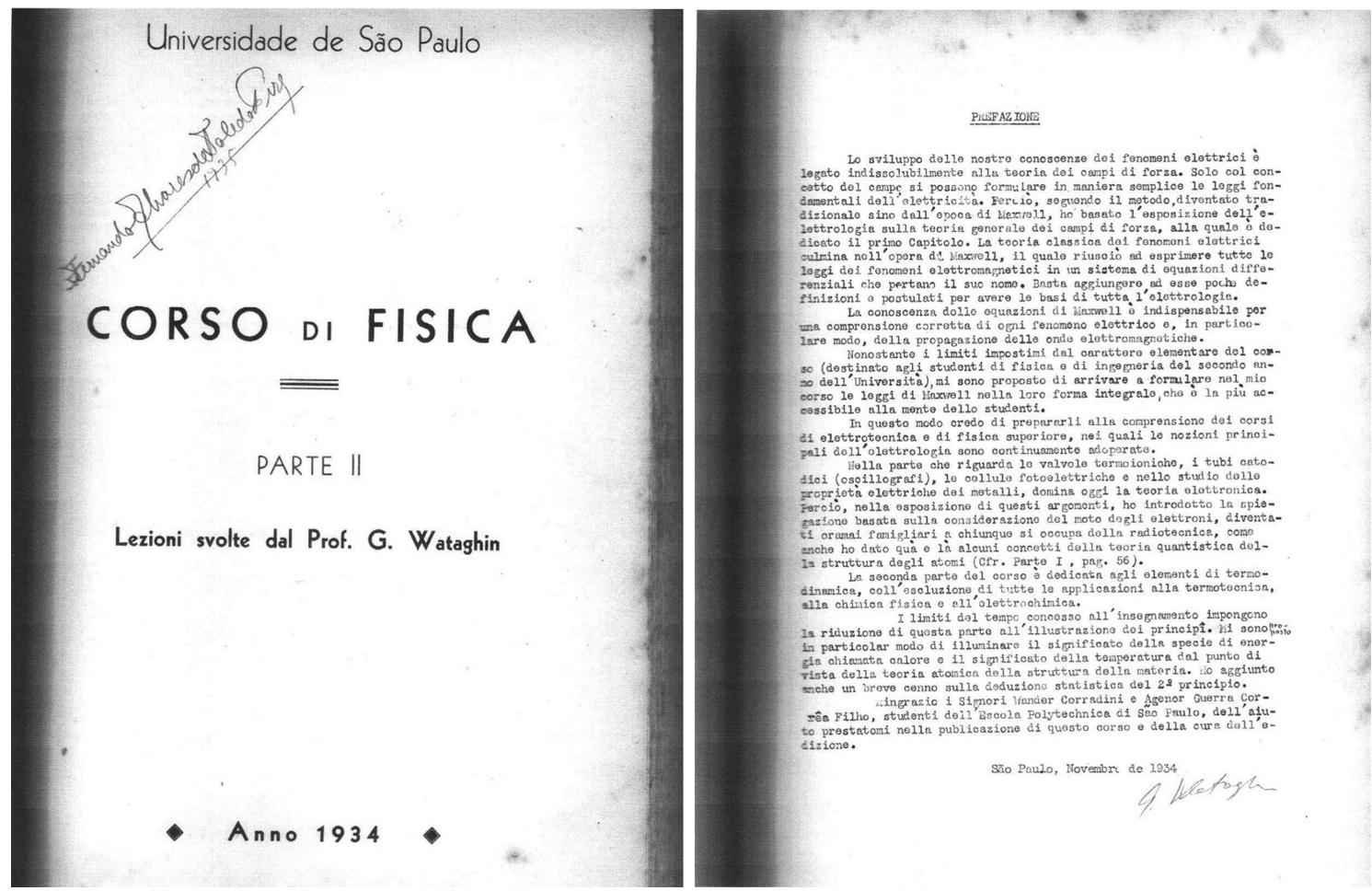

Figura 1: Folha de rosto e prefácio da segunda parte do curso de física ministrado por Gleb Wataghin para a Escola Politécnica em 1934. Esta cópia foi usada por um aluno no ano de 1935. Nela não há folha de rosto ou prefácio para a primeira parte. No último parágrafo do prefácio, datado de novembro de 1934, lê-se: "Ringrazio i Signori Wander Corradini e Agenor Guerra Corrêa Filho, studenti dell'Escola Polytechnica di São Paulo, dell'aiuto prestatomi nella publicazione di questo corso e della cura dell'edizione.".

pliava para mais de apenas um o número possível de posições de 'fim de carreira' (a partir de então denominadas 'professor titular') em cada uma dessas "menores frações da estrutura universitária" criadas em substituição às cátedras. (Numa frase que circulou na época, eventualmente atribuída a professor da nova Faculdade de Filosofia, Letras e Ciências Humanas, a reforma "substituiu as cadeiras por sofás"). Além disso, a reforma instituía também Ciclos Básicos, a serem oferecidas pelos departamentos a estudantes "de várias carreiras afins, em vez de disciplinas semelhantes para cada carreira como era até então" [4]. Esta última decisão não foi, no entanto, implementada na USP, embora a departamentalização tenha levado à criação de uma nova unidade, o Instituto de Ciências Biomédicas, para desempenhar com relação às antigas escolas superiores da área da saúde papel análogo ao que havia sido atribuído à Faculdade de Filosofia, Ciências e Letras com relação às demais escolas por ocasião da criação da universidade. Desse modo, esse novo instituto recebeu o espólio das cátedras básicas das escolas da área de saúde, e com elas a responsabilidade pela ministração das correspondentes disciplinas básicas, além do desenvolvimento de pesquisa fundamental no seu âmbito. Diferentemente do que ocorrera no caso anterior, no entanto, não houve a criação concomitante de cursos para a formação de professores e novos pesquisadores. A vinculação dos alunos às respectivas escolas foi também mantida por ocasião da criação dessa nova unidade, que foi portanto criada 'sem alunos' (entenda-se sem seus próprios alunos, no sentido das demais unidades) embora com extensas responsabilidades didáticas. Vale a pena lembrar que, na adaptação da USP à reforma de 1968, a unidade integradora da época da fundação, a Faculdade de Filosofia, Ciências e Letras, foi desmembrada nos quatro institutos de Biologia, Química, Física e Matemática, mais a Faculdade de Filosofia, Letras e Ciências Humanas; e que cada uma dessas novas unidades surgia equipada com cursos e alunos herdados de sua matriz comum, no que se equiparavam ao status das unidades descendentes das antigas escolas superiores.

Do ponto de vista da estrutura da universidade, a decisão de manter um sistema curricular que continu- 
ava requerendo o oferecimento pelas novas unidades universitárias de "disciplinas semelhantes para cada carreira", preservou as próprias "carreiras" como clivagens internas suficientes para manter a identidade das diferentes escolas superiores envolvidas na criação da universidade. Este resultado pode mesmo ter atuado como motivação importante, embora não explícita para a diferenciação de disciplinas "por carreira". Isso levou no entanto a consequências importantes também para a forma pela qual a universidade se apresenta aos estudantes, ao manter a integração conseguida através da implementação da estrutura departamental efetivamente desconectada das oportunidades oferecidas a eles. Estas, de fato, continuaram sendo apresentadas como um elenco prefixado de opções de "carreiras", ou cursos, definidos por currículos elaborados nas unidades para seus alunos, uma vez chancelados pelos órgãos centrais. As opções têm se tornado ao longo do tempo progressivamente, se mais variadas, também mais exclusivas, apenas com oportunidades limitadas pela circunscrição das escolhas possíveis a domínios prédeterminados e tipicamente bastante restritos. Em outras palavras, a capacidade formativa instalada na universidade como um todo se mantém, como tal, inacessível aos estudantes de graduação, cujas oportunidades de interação são institucionalmente limitadas a pequenos setores tidos como apropriados à escolha de "carreira", ou de curso, feita por ocasião do seu procedimento de ingresso.

A elaboração e regulamentação de cursos de pósgraduação na universidade de São Paulo se deu a partir de meados dos anos 60, antes portanto da reforma de 1968 e do novo Estatuto de 1969. O setor de pós-graduação foi tratado já no início como tendo grande autonomia, sendo em particular independente não apenas do arcabouço administrativo ligado aos cursos de graduação, mas até da própria estrutura departamental. Isso foi feito com a instituição de áreas de concentração, definidas dentro das unidades universitárias. O instituto de Física, em particular, com seus então já vários departamentos, optou de início por manter uma única área de concentração denominada "Física teórica e experimental". As disciplinas a serem oferecidas para satisfazer os requisitos de créditos para programas de mestrado e doutorado podiam ser propostas livremente por docentes, que por um tempo considerável foram tratados como 'donos' da disciplina proposta. Dizia-se mesmo, após a extinção das cátedras, que considerar dessa forma 'professores de tal ou qual disciplina de pós-graduação' revelava de certa forma o seu ressurgimento. Em pouco tempo o título pós-graduado de doutor se tornou requisito corrente para a ocupação de posições acadêmicas com responsabilidades, além de docência, também de pesquisa. A obtenção desse título exigia, além da elaboração e defesa de um trabalho de pesquisa original, a aprovação em cursos em um total que, por si só, exigia um período da ordem de dois anos para ser cumprido. Vista desse ângulo, a regulamentação da pós-graduação efetivamente retardou o envolvimento com a atividade de pesquisa propriamente dita de estudantes interessados em seguir uma carreira de pesquisador.

\section{O Curso Experimental de Ciências Moleculares}

\subsection{Início}

No ano de 1990, início da gestão de Roberto Leal de Lobo e Silva Filho, do Instituto de Física de São Carlos, na reitoria da universidade de São Paulo, o impulso inicial para a criação de um curso de graduação em novos moldes prece ter sido provocado por uma elaboração convergente de preocupações com talvez três questões distintas. Essas questões teriam sido, por um lado, 1) a ausência de um curso voltado à formação de pesquisadores na área das ciências da saúde; por outro lado 2) a longa duração do processo formativo de novos pesquisadores, tendo em conta as exigências impostas pela regulamentação da formação em nível de pós-graduação; e, finalmente, 3) o caráter 'federativo' da universidade, limitando bastante interação envolvendo partes 'independentes' da estrutura da universidade. A própria origem da proposta de criação envolveu já alguma ruptura com os padrões 'normais' da universidade, segundo o então pró-reitor de pesquisa, Erney Plessmann de Camargo, do Instituto de Ciências Biomédicas em entrevista concedida por ocasião do septuagésimo aniversário da universidade [5]:

(... ) Coisas interessantes dessa gestão: em primeiro lugar, essas ideias que fugiam da normalidade, por exemplo, quando se cria um curso, o caminho normal é a unidade criá-lo, normalmente é igual a um monte de cursos que já existem por aí, etc. Mas não, nessa gestão a primeira proposta que surgiu foi minha, 
foi a criação do curso de Ciências Moleculares, que era um curso totalmente diferente.

A ideia, juntamente com a sua motivação, tinham sido tratadas pouco antes, nessa mesma entrevista 6]:

Outra coisa que nós criamos foi o curso de Ciências Moleculares, que envolvia matemática, física, biologia e química, é voltado para alunos que passaram no vestibular e querem fazer ciência desde o começo, não era exatamente um curso tradicional. Quando pensei nesse curso, junto com o Lobo, pensei muito na minha própria formação; como já falei, fui fazer Medicina, mas queria mesmo é fazer ciência e não havia exatamente onde fazer isso. O curso de Ciências Moleculares funciona até hoje, os alunos que saem dele são brilhantes, absolutamente atualizados com a ciência contemporânea, poderia ser melhor apoiado pelas gestões que nos sucederam, não foi, mas mesmo assim sobreviveu e está muito bem.

A palavra do reitor Lobo (um físico) a respeito do curso se encontra em uma entrevista de fins de 1990, antes do início do seu funcionamento [7]:

O curso surgiu de duas preocupações principais. A primeira é o tempo muito longo que se leva no Brasil para formar uma pessoa. E a segunda é a segmentação muito grande que há nos cursos tradicionais.

No Brasil uma pessoa faz quatro anos de graduação sendo que [em] dois deles ela repete o conteúdo do vestibular e depois, às vezes, mais quatro de mestrado, cinco de doutorado. É uma formação muito longa. E a pessoa perde a época mais criativa da vida fazendo cursos, quando a gente tem certeza de que a pessoa disposta a seguir a área de ciência mesmo, precisa fazer uma formação muito mais rápida. (...)

A Física, por exemplo, tem o seu curso. Mas não tem uma integração com a Química, com a Biologia. Então o curso de cientista [expressão que fornece o título com o qual e entrevista é publicada] tem o objetivo de fazer uma programação interdisciplinar. Que a pessoa conhecesse os fundamentos da Física e que isso fosse ligado ao que acontece na Química e a Química mostrasse o que acontece na Biologia. A pessoa teria uma visão dessas três áreas e das correlações entre as três coisas.

A interdisciplinaridade seria implementada envolvendo recursos já existentes em diferentes unidades da universidade, nas áreas de matemática (incluindo técnicas de computação), física, química e biologia. Na mesma entrevista [7], em resposta à questão da necessidade de novos recursos para a implementação do curso, o reitor Lobo diz:

A ideia é não contratar ninguém e não comprar nada porque temos laboratórios de ensino já muito bem instalados. Talvez uma ou outra coisinha. Usaríamos, então, os laboratórios da Química, Física, da Biologia quando necessários. Pode ser que falte alguma coisa na região de integração, mas coisas menores, de custo absolutamente marginal. É só uma mudança de atitude.

A configuração finalmente adotada instituía um ciclo básico inicial com duração de dois anos letivos nos quais as disciplinas ministradas seriam matemática, física, química e biologia, além de duas outras disciplinas 'instrumentais', computação e inglês. As disciplinas do ciclo básico seriam ministradas por pesquisadores ativos em suas áreas, cedidos para isso por suas unidades de origem. Cada um dos estudantes admitidos teria um docente da universidade como 'tutor', com o intuito de propiciar orientação e apoio quando necessário, e receberia uma bolsa de estudos. Ao fim desse ciclo básico, cada estudante escolheria um orientador para um programa personalizado de iniciação científica, juntamente com quem proporia um currículo complementar, designado como 'ciclo avançado', sujeito a aprovação pela direção acadêmica do curso, para o qual poderia cursar, em princípio, qualquer das disciplinas oferecidas por qualquer das várias unidades universitárias. Este currículo complementar deveria incluir obrigatoriamente, em sua carga horária programada, 
o desenvolvimento do plano de iniciação científica acertado com o professor orientador.

Não é difícil ver que uma tal proposta trazia vários aspectos bastante inusitados no funcionamento costumeiro da universidade. O primeiro deles é o de o curso não estar vinculado a qualquer unidade universitária, afim de manter a devida simetria entre as diferentes unidades, já existentes, que dele participassem. A vinculação finalmente adotada foi à própria pró-reitoria de graduação, o que é mantido até o presente. Além de demandar uma carga de trabalho adicional de algumas unidades no que se refere à ministração das disciplinas do ciclo básico multidisciplinar e às atividades de tutoria e orientação, a proposta criava ainda uma região de contacto, com demandas novas e específicas de integração e coordenação, entre as diferentes unidades envolvidas. Finalmente, no que se refere ao ciclo avançado, a proposta efetivamente abria aos estudantes do novo curso experimental o acesso basicamente irrestrito às disciplinas ofertadas por, no mínimo, todo o setor de ciências exatas e da natureza da universidade. É claro que isso, em contrapartida, colocava demandas novas sobre a estruturação interna das unidades quanto à sua disponibilidade para receber estudantes externos em suas disciplinas. Não é preciso lembrar que tal liberdade de escolha não é disponível hoje para os estudantes arrolados nos cursos oferecidos pelas diferentes unidades da universidade. Todos esses aspectos exigiram, por vários anos, um trabalho continuado de compatibilização e integração com a operação corrente não apenas do setor de graduação mas também com o de pós-graduação da universidade.

\subsection{Inserção na universidade e legalização}

A datação da criação efetiva do Curso de Ciências Moleculares ou, na sua denominação inicial, do Curso Experimental de Ciências Moleculares, depende fortemente de como se queira definir o que possa ter sido o momento em que a criação se efetiva. A escolha usualmente adotada corresponde à primeira instância de oficialização, que é a aprovação do curso pelo Conselho de Graduação (CoG) da universidade. Há documentos (v. fig. 2) dando a data dessa aprovação como sendo 18 de outubro de 1990, portanto antes do fim do primeiro ano da gestão Lobo na reitoria da universidade. Outra data mais frequentemente citada de refere à da Resolução do CoG divulgando deliberação anterior desse mesmo

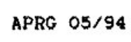

CURSO DE CIENCIAS MOLECULARES

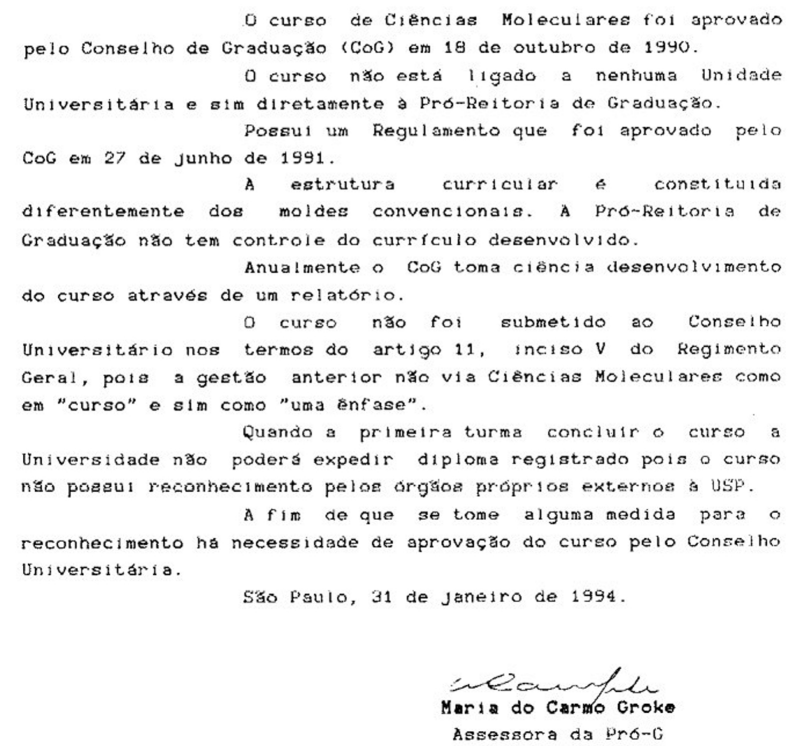

Figura 2: Documento APRG05/94, de 31 de janeiro de 1994, da Assessoria da Pró-Reitoria de Graduação

Conselho no sentido de aprovar o Regulamento do curso. De fato, a Resolução CoG 3836 de 3-7-91 foi o primeiro documento relativo ao curso a chegar às páginas do diário oficial, o que ocorreu na edição de 5 de julho de 1991. Essa Resolução aprova, "em vista do deliberado pelo Conselho de Graduação, em sessão de 27-6-91, o Regulamento do Curso Experimental de Ciências Moleculares". Foi isso, de fato, o que na realidade ensejou o início do funcionamento do curso com a seleção de sua primeira turma de alunos.

A denominação do curso e sua finalidade são dados no artigo $1^{o}$ do Regulamento:
Artigo $1^{o}$ - O Curso Experimental de Ciências Moleculares (CECM) tem como objetivo a formação de profissional espe- cializado em investigação científica em Ciências Moleculares.

A denominação tem sido objeto de numerosas e variadas análises, exegeses e até mesmo chistes (ciências o que?) [8]. O que pode ser visto como uma análise (ou exegese?) precoce foi exposto por um dos criadores do curso, o reitor Roberto Lobo, durante sua 
participação do programa Roda Viva da TV Cultura em 21 de dezembro de 1991 [9]. Nesse tempo o curso estava já em funcionamento, tendo o primeiro período letivo da primeira turma sido iniciado no mês de setembro do mesmo ano.

\section{(...) Esse projeto [referindo-se ao CECM]} é um curso experimental, e que procura fazer com que o estudante, motivado e capaz, chegue rapidamente à fronteira do conhecimento na área molecular. A molécula é parte da vida, e é parte do ser inanimado também. Tem moléculas em todos os lugares, não é? A ideia é dar uma formação forte de física, voltada à área molecular, uma forte formação de química, voltada à área molecular e uma forte formação de biologia, também voltada à área molecular. Então, essa pessoa será capaz de integrar conhecimento, sempre pensando na estrutura da matéria, e que ele junta conhecimento da física, da química e da biologia, em um nível avançado. Nós queimamos todas as etapas pré-vestibular. Achamos que aquilo tem que ser sabido, se ele não sabe alguma coisa, ele vai ter que voltar a estudar por conta própria. (...)

$\mathrm{O}$ artigo $3^{\circ}$ trata do posicionamento do curso no no organograma da universidade:

\section{Artigo 3o - O CECM está vinculado di-} retamente à Pró-Reitoria de Graduação.

Os doze artigos seguintes tratam da estrutura administrativa do curso. Resumidamente, são criados três níveis administrativos. O nível mais alto consiste de um Conselho Diretor, com reuniões ordinárias anuais, sendo sua missão supervisionar o CECM, designar os membros dos níveis administrativos inferiores, além de tratar da estrutura curricular e da normatização do processo de seleção. Esse Conselho Diretor é constituído pelos pró-reitores de graduação, pós-graduação e pesquisa, mais o diretor científico da FAPESP e os diretores das unidades associadas ao ciclo básico do curso, sendo citados os institutos de Biociências, Ciências Biomédicas, Física e Química (a publicação não inclui o instituto de Matemática e Estatística ${ }^{1}$, além de representação discente. Com

\footnotetext{
${ }^{1}$ Esta omissão foi corrigida apenas no primeiro ano do mandato reitoral subsequente, em uma nova Resolução do CoG, a de
}

direito a voz, mas não a voto, são incluídos ainda os integrantes da Comissão Coordenadora (CC). Esta corresponde ao segundo nível administrativo. A ela cabe a direção do curso tanto no que se refere a questões acadêmicas como logísticas, sendo constituída por "nove pesquisadores da USP" mais representação discente, tendo o pró-reitor de pesquisa como seu presidente nato. O terceiro nível administrativo ou, dir-se-ia, o nível executivo, é instituído como Coordenação de Curso, constituída de um Coordenador, um Assistente Acadêmico e uma Secretária. O primeiro Coordenador do CECM foi Hernan Chaimovich, do Instituto de Química da universidade.

Os dois últimos títulos do Regulamento tratam das disposições referentes ao corpo discente e ao corpo docente. As disposições referentes ao corpo discente são

Artigo 13 - Poderão ser admitidos ao CECM quaisquer alunos regularmente matriculados nos diversos cursos da USP, em qualquer período letivo de sua carreira.

Artigo 14 - O ingresso no CECM se dará por transferência, após classificação no concurso vestibular da USP e matrícula numa Unidade Universitária.

Parágrafo único - $\mathrm{O}$ aluno que desistir do CECM, que não apresentar rendimento satisfatório ou que concluir o CECM poderá retornar à sua unidade de origem afim de completar o curso matriculado preliminarmente (sic).

Artigo 15 - O cancelamento de matrícula terá as normas vigentes na USP.

Artigo 16 - Cada aluno terá um tutor designado pela Comissão Coordenadora (CC).

número 4112 de 26-08-94, publicada em substituição à anterior pelo novo pró-reitor de graduação, Carlos Alberto Dantas, do Instituto de Matemática e Estatística. A versão revista do Regulamento do CCM incorpora também o conteúdo da Resolução CoG-3927/92 que determina a o cômputo das horas de aula ministradas no CECM para a carga didática dos respectivos docentes em sua unidade de origem(v. pag. 10). Foi a versão de 1994 do Regulamento que serviu de base para a aprovação do CECM pelo Conselho Universitário e em seguida pelos conselhos Estadual e Federal de Educação (v. pag. 8. 
Artigo 17 - A avaliação do rendimento escolar seguirá as normas vigentes na USP.

Apenas o último artigo se refere ao corpo docente:

Artigo 18 - Os professores que ministram disciplinas do CECM serão designados para tal fim pelo Pró-Reitor de Graduação, por proposta da CC, com anuência do Diretor da Unidade de origem.

Não é difícil perceber que esse artigo resolve mal o problema de assegurar a contribuição de docentes de diferentes unidades para ministrar as disciplinas do novo curso experimental. De fato, ele trata o diretor da unidade como seu representante junto à pró-reitoria (ou junto à comissão coordenadora?) no processo de designação. Nessa época, em muitas unidades a distribuição de encargos didáticos era tratada em nível departamental, sendo as diferentes disciplinas ministradas pela unidade também repartidas departamentalmente. Uma exceção era o Instituto de Física, onde vigorava um chamado 'acordo de cavalheiros' pelo qual os departamentos abriam mão de distribuir os seus docentes por suas disciplinas, ficando a tarefa de distribuir os encargos didáticos do Instituto pelo conjunto de todos os docentes do Instituto entregue à Comissão de Graduação igualmente do Instituto. Apenas passada a excepcionalidade do caso dos primeiros períodos letivos da primeira turma, o conflito se manifestou através da recusa de departamentos contabilizarem os encargos didáticos de seus docentes quando alocados para o CECM, levando-os por isso a recusar tais encargos. ${ }^{2}$

Deve ser observado aqui, ainda que apenas entre parênteses, que de acordo com o regimento geral da universidade, a resolução do CoG não completa a criação do curso, que passa a depender ainda de uma aprovação pelo Conselho Universitário (Co), indispensável para que ela possa ser apreciada por sua vez pelos órgãos validadores externos à universidade (Conselho Estadual e Conselho Federal de Educação), que conferem reconhecimento completo ao curso. A submissão da criação do CECM ao Co, no entanto, se deu apenas em 1994, já durante o mandato reitoral de Flávio Fava de Moraes. A existência

\footnotetext{
${ }^{2}$ Esse não era, nos primeiros anos de funcionamento do CECM, a única dificuldade em assegurar a contribuição de docentes das unidades participantes do curso, v. pag. 10 a respeito.
}

de algum tipo de resistência no âmbito da administração central da universidade que possa ter levado a tal atraso é claramente indicada nos três últimos parágrafos do documento reproduzido na fig. 2, datado do início da administração Fava de Moraes na reitoria da universidade, e que tem características de resposta a uma eventual inquirição acerca da situação formal do curso naquele momento:

O curso não foi submetido ao Conselho Universitário nos termos do artigo 11, inciso V do Regimento Geral, pois a gestão anterior não via Ciências Moleculares como em (sic) "curso" e sim como "uma ênfase".

Quando a primeira turma concluir o curso a Universidade não poderá expedir diploma registrado pois o curso não possui reconhecimento pelos órgãos próprios externos à USP.

A fim de que se tome alguma medida para o reconhecimento há necessidade de aprovação do curso pelo Conselho Universitária (sic).

A aprovação pelo Co se daria em 19 de outubro de 1994. A ela sobrevieram a aprovação pelo Conselho Estadual de Educação, em 27 de março de 1996 e uma autorização de funcionamento do curso conferida através da Portaria Ministerial no 613 de 13 de junho de 1996 do Ministro de Estado da Educação e do Desporto, publicada no Diário Oficial da União de 14/06/96. Vale lembrar que a primeira turma do CECM concluíra o curso um ano antes, e que alguns de seus integrantes se encontravam já engajados em programas de pós-graduação no exterior. A consequência de ter sido completado o processo de reconhecimento oficial do curso foi a possibilidade de finalmente expedir 'diplomas registrados' para os egressos do curso. Isso foi feito também, retroativamente, para os alunos da primeira turma. Os meandros envolvidos nesse processo de completar o reconhecimento oficial do curso de Ciências Moleculares será abordado de forma mais pormenorizada adiante (v. pag. 14 e seguintes).

As disposições do Regulamento referentes ao corpo discente (artigos 13 a 17) de fato apenas implementam as concepções originais dos criadores do curso. De fato, nas palavras do reitor Lobo na entrevista de 19907 
(...) nossa ideia é não criar um curso novo, no sentido por exemplo de novas vagas, de ser ofertado no vestibular. O que vamos fazer é oferecer um certo número de vagas para os alunos que já ingressaram na faculdade - seja em Física, Química ou Biologia. Quem quiser fazer essa experiência junto conosco que se candidate.

A época escolhida para os processos de seleção para o CECM foi o início do segundo semestre de cada ano, coincidindo portanto com o término do primeiro semestre letivo da universidade. Através de um acordo acertado entre os fundadores do curso e o CNPq, todos os estudantes admitidos para o CECM se tornariam automaticamente bolsistas de iniciação científica. A aderência a esse acordo se estendeu de fato por alguns anos, até que sua manutenção se tornasse progressivamente mais problemática, inclusive pela rotatividade dos ocupantes das instâncias envolvidas no acerto inicial.

A primeira seleção, levada a efeito em 1991, contou com a participação convidada de uma psicóloga, ao que me consta especializada em questões de seleção de 'recursos humanos'. Ela teria então, com base em seus critérios, sido contrária, em particular, à admissão de uma candidata proveniente do Instituto de Física, que foi no entanto finalmente admitida após manifestação firme do professor Henrique Fleming de que ela havia sido sem dúvida sua melhor aluna na disciplina de física básica que havia ministrado no período imediatamente anterior à seleção. O sucesso posterior dessa estudante pode ter contribuído para o abandono da arregimentação de técnicas, digamos, 'empresariais' no contexto do processo seletivo de alunos para o curso.

Por ocasião do estabelecimento do curso, foi também criado pela Fundação Itaú um fundo denominado Fundo Lúcio Martins Rodrigues para apoiar o funcionamento do curso. Esse fundo se deveu a contatos diretos entre o professor Alexandre Martins Rodrigues e Olavo Setúbal, que fora aluno do professor Lúcio Martins Rodrigues na escola Politécnica e decidiu homenageá-lo quando solicitado pelo professor Alexandre Martins Rodrigues a escolher a denominação do fundo que havia criado.

O local escolhido para sediar o CECM foi o Favo 22 do conjunto de edificações denominado Colmeias, no caso de favos octogonais dispostos segundo uma rede quadrada, onde o curso funciona até os dias de hoje. Embora tal localização tenha sido muitas vezes discutida, tendo em vista, por exemplo, o distanciamento dos prédios onde se desenvolvem atividades acadêmicas relevantes para o curso, ela parece ter contribuído positivamente para a preservação de uma identidade própria para o curso. Desde a sua instalação, o Favo 22 sofreu já dois processos bastante extensos de reforma para melhor adaptá-lo à sua função.

\section{O ciclo básico e seu conteúdo curricular}

Uma peculiaridade incluída na formatação inicial das disciplinas a serem oferecidas no ciclo básico do CECM consistiu em que, diferentemente da prática comum na universidade de subdividir cada ano letivo em dois semestres letivos, os anos letivos do CECM foram subdivididos em três quadrimestres letivos. O primeiro se estendia de meados de setembro a meados de dezembro, o segundo do início de fevereiro a meados de maio e o terceiro do início de junho a meados de agosto. A razão para isso não é clara, estando possivelmente ligada à ideia de flexibilizar a estruturação curricular do curso. Outra peculiaridade foi a atribuição a cada uma das disciplinas de um único período de todo um dia por semana. Ela foi apresentada como uma das características distintivas do curso pelo reitor Lobo também no já mencionado (v. pag. 7) programa Roda Viva de 21 de dezembro de 1991 [9]:

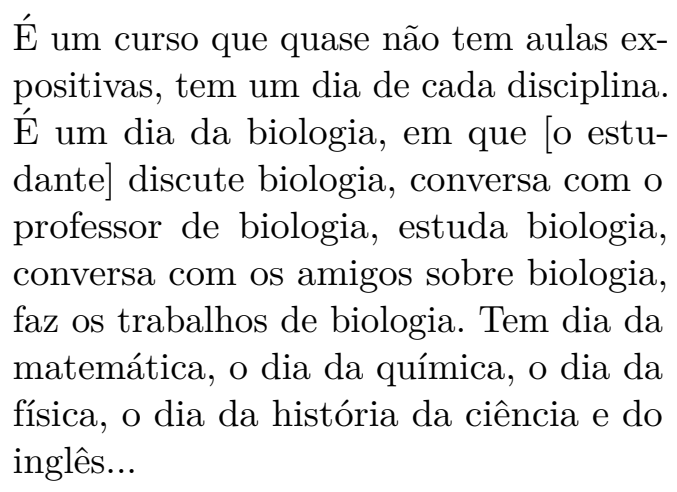

Isso sugere não se tratar de alguma opção meramente circunstancial, mas de um ingrediente introduzido explicitamente no planejamento inicial do curso pelos seus criadores, e que deveria abranger todas as disciplinas. Um possível polo motivador para tal opção pode ter sido a utilização frequente de grandes blocos horários em disciplinas com ex- 
tensa atividade de natureza prática ministradas na área biológica.

Devido, em particular, ao descompasso criado entre os períodos letivos do CECM relativamente aos períodos letivos normais da universidade, essas duas disposições levaram desde logo ao agravamento da dificuldade em obter aquiescência em suprir a nova demanda por parte tanto de docentes como de órgãos de administração das unidades universitárias envolvidas na operação do ciclo básico do CECM. Tratou-se, na realidade, apenas de um agravamento. A dificuldade básica resultou de fato na insuficiência do que dispunha o artigo 18 da do Regulamento aprovado pelo $\mathrm{CoG}$, face à recalcitrância, e mesmo à recusa de departamentos em ter em conta o trabalho de seus docentes junto ao CECM na contabilização de sua carga de trabalho didático. Isso levou de fato à publicação de uma nova Resolução, a Resolução CoG-3927 de 29-4-92, que adicionava à Resolução referente ao Regulamento do CECM disposições segundo as quais "A carga horária dos professores, na Unidade de origem, incluirá as horas de aula e as demais atividades realizadas no CECM", e também que "A carga horária e as demais atividades do CECM serão computadas pelo Departamento de origem dos professores, para os efeitos da política de contratação de docentes na Universidade". Apesar do intuito pacificador da segunda dessas disposições, a aderência às determinações dessa Resolução, especialmente à primeira delas, mostrou-se sempre bastante frágil ao longo de todo o funcionamento de curso, tendo sido necessário muitas vezes reinvocar a intercessão de sua existência junto às unidades envolvidas no ciclo básico do curso.

\subsection{As disciplinas do ciclo básico}

A escolha das disciplinas a serem ministradas no ciclo básico e a elaboração dos respectivos programas envolveram, além dos propositores do curso, um grupo de professores de diferentes unidades da universidade. Sem que isso seja uma lista completa, pertenceram a esse grupo os professores Alexandre Martins Rodrigues do Instituto de Matemática e Estatística, Henrique Fleming e Luís Carlos Gomes do Instituto de Física e Newton da Costa, então da Faculdade de Filosofia, Letras e Ciências Humanas, tendo pertencido anteriormente ao Instituto de Matemática e Estatística. Dentro do pressuposto de um ano letivo subdividido em três quadrimestres, o currículo do ciclo básico compreendendo dois anos letivos foi definido como incluindo seis disciplinas de Matemática, uma disciplina de Laboratório de Física mais seis disciplinas de Física, cinco disciplinas de Química (uma das quais sendo declarada disciplina de laboratório), cinco de Biologia, uma de Computação e uma de Filosofia da Ciência, com o subtítulo "Fundamentos da Matemática e das Ciências Naturais". No caso da primeira turma, as disciplinas de Computação e Filosofia da Ciência foram oferecidas no primeiro quadrimestre, juntamente com as primeiras disciplinas de Matemática, Física e Biologia. A disciplina 'instrumental' denominada Computação foi implementada por Jorge Lacerda de Lyra, a pedido do coordenador do curso 10 . No segundo quadrimestre foram oferecidas as disciplinas de Matemática, Física, Biologia e a primeira disciplina de Química, além do Laboratório de Física. Nos três quadrimestres seguintes foram oferecidas as disciplinas de Matemática, Física, Biologia e Química, enquanto no sexto e último quadrimestre do ciclo básico foram oferecidas as disciplinas de Matemática, Física e Química.

O fato de que as ementas para as disciplinas do ciclo básico foram preparadas por professores ligados a diferentes domínios da universidade se reflete visivelmente numa não uniformidade de estilo. Por exemplo, a multiplicidade de indicações bibliográficas e a relativa laconicidade das ementas de Física tornam o seu poder indicativo muito mais vago que no caso das ementas de Matemática. Estas consistem de uma sequência de quatro quadrimestres de 'cálculo' entremeados de dois quadrimestres de álgebra linear, em todos os casos com indicações bibliográficas únicas. Uma peculiaridade nas ementas das disciplinas de Física é a curiosa composição dada como programa para o terceiro quadrimestre:

\section{PRG231 Física \\ (...)}

Bibliografia: Feynman, R. P., Lectures on Physics, vol.1; Nussenzveig, H. M., Curso de Física Básica, vol. 2.

Programa: Princio de Fermat. Tratamento a la Feynman da radiação eletromagnética. Interferência. Equação de Schrödinger. Função de onda. Partícula na caixa. Tunelamento em uma dimensão. Teoria cinética dos gases. Leis da Termodinâmica. Processos termodinâmicos em fluidos perfeitos. Equilíbrio químico entre gases. 
A ementa para a disciplina de Filosofia da Ciência é claramente uma contribuição pessoal do professor Newton da Costa:

\section{PRG520 Filosofia da Ciência}

Fundamentos da Matemática e das Ciências Naturais

$(\ldots)$

Bibliografia: Boolos, G. S. e Jeffrey, R. C., Computability and Logic, $2 \underline{\text { nd }}$ edition, Cambridge University Press, 1987.

Programa: Enumerabilidade e diagonalização. O conceito de algorítmo, máquinas de Turing e Tese de Church. Funções recursivas, conjuntos recursivos, conjuntos recursivamente enumeráveis e o problema da auto-parada. Elementos de lógica de $1 \underline{a}$ ordem: linguagens de $1 \underline{a}$ ordem, interpretações, modelos, consequência semântica e forma normal prenex. Derivabilidade, correção e completude. O sistema de Robinson a representabilidade de funções recursivas. Teorema da indecidibilidade de Church, teorema da indefinibilidade de Tarski e Teorema de incompletude de Gödel. Indecidibilidade e incompletude de teorias científicas.

Essa disciplina foi ministrada uma única vez em toda a história do curso, durante o primeiro quadrimestre letivo oferecido para a primeira turma, pelo próprio professor Newton da Costa.

\subsection{O ciclo básico visto por dentro}

Coube a mim, em 1992, a incumbência de oferecer as disciplinas de física de primeiro ano aos alunos selecionados para a segunda turma do CECM. Além disso, fui designado tutor de um dos estudantes dessa mesma turma. Foi nessa ocasião e circunstância que se deu meu primeiro contacto por assim dizer 'interno' com o ciclo básico em funcionamento.

A segunda turma do CECM contava inicialmente com oito estudantes, entre os quais ocorreu uma desistência antes do fim do primeiro quadrimestre. O horário alocado para a disciplina de Física era, como já foi dito, o de todo um único dia por semana, no caso todas as terças-feiras, das 8 às 12 horas e das 14 às 18. Isso foi parcialmente mudado, a partir de 19 de outubro, quando à disciplina de Física passou a ser alocado o horário menos extremado de terças e quintas-feiras das 8 às 12 horas, mediante negociação complementar com uma das outras disciplinas. A aula da terça-feira, 28 de setembro de 1992 foi cancelada devido à votação na Câmara dos Deputados relativa ao impeachment do então presidente Fernando Collor de Melo.

Com a memória, então recente, de que, antes e em preparação da instalação do curso e da seleção da primeira turma, um ano antes, o professor Luís Carlos Gomes desenvolvia com seu característico entusiasmo a ideia de alterar completamente a programação, digamos, tradicional das disciplinas de física básica, iniciando-as com a introdução de física quântica, no espírito do volume III das Feynman Lectures 3 , era necessário, antes de mais nada, definir de forma mais, digamos, realística o conteúdo das disciplinas. Para isso, pedi ao professor Henrique Fleming, que não só participara da elaboração do curso mas também ministrara as mesmas disciplinas para a primeira turma, informações sobre o programa 'real' que fora usado. Em resposta a isso, recebi dele, manuscrita, a relação reproduzida abaixo, correspondente ao primeiro quadrimestre:

Programa real de Física (1991-1992)

Feynman, Vol. 1

$$
\begin{aligned}
& \text { Cap. } 1 \text { - Atoms in Motion } \\
& \text { Cap. } 4 \text { - Conservação de energia } \\
& 5 \text { - Time and distance } \\
& 6 \text { - Probability } \\
& 7 \text { - The theory of gravitation } \\
& 8 \text { - Motion } \\
& 9 \text { - Newton's Laws of Dynamics } \\
& 10 \text { - Conservation of Momentum } \\
& 11 \text { - Vectors } \\
& 12 \text { - Characteristics of Force } \\
& 13 \text { - Work and Potential Energy A } \\
& 14 \text { - Idem B } \\
& 18 \text { - Rotations in Two Dimensions } \\
& 19 \text { - Center of Mass; Moment of } \\
& \text { Inertia }
\end{aligned}
$$

\footnotetext{
${ }^{3} \mathrm{Um}$ resíduo dessas ideias pode ter sobrevivido no programa oficial para o terceiro quadrimestre da disciplina de física PRG231, citado na pag. 10 .
} 
20 - Rotation in Space

21 - The Harmonic Oscillator

\author{
22 - Algebra (números complexos, \\ basicamente)
}

23 - Resonance

24 - Transients

25 - Linear Systems and Review

Esse foi então o programa $a^{4}$ que usei para o primeiro quadrimestre da disciplina de Física para a segunda turma do CECM, a partir de 14 de setembro de 1992. A referência ao texto (Feynman, Vol. 1) não significa necessariamente uma aderência estrita a ele, mas além de elencar os assuntos a serem tratados, dá indicações relevantes também sobre o nível de detalhamento e rigor conceitual a ser buscado.

Os oito tópicos finais (itens 18 a 25 inclusive) do programa 'real' correspondente ao primeiro quadrimestre constituíam na realidade o programa previsto oficialmente para o segundo quadrimestre. Este teve portanto que ser realizado com um programa diferente, que segundo minhas anotações foi iniciado com a propagação ondulatória e equações de onda em meios materiais. Os efeitos de mudanças galileanas de referencial sobre as equações de onda e o comportamento observado de ondas eletromagnéticas no vácuo motivaram a apresentação da teoria restrita da relatividade.

O terceiro quadrimestre foi dedicado à física térmica e à teoria cinética dos gases. Foi a essa altura que, vendo a presença considerável de ideias da termodinâmica em textos utilizados seja nas disciplinas de química, seja nas de biologia, tratadas de um ponto de vista muito distinto do que estava usando na disciplina de física, ocorreu-me propor ao coordenador do curso que buscasse promover reuniões informais entre docentes das várias disciplinas afim de facilitar a explicitação de conexões para os estudantes. Apesar da resposta positiva e rápida do coordenador, os pouquíssimos encontros efetivamente ocorridos não

\footnotetext{
$\overline{{ }^{4} \text { Vale a pena comparar }}$ com a caracterização oficial para a disciplina PRG211 que, mesmo em se tratando de uma situação admitidamente experimental e nova, se aproxima notavelmente do grau de indefinição comum em (praticamente) todas as disciplinas oferecidas pelo Instituto de Física (até) hoje: Bibliografia: Feynman, R.P.,Lectures on Physics, vol.1; Nussenzveig, H.M. Curso de Física Básica, vol 1. Programa: Cinemática Vetorial. Conservação de Energia. Princípio do trabalho virtual e aplicaçôes à estática. Leis de Newton. Gravitação. Conservação do momento linear. Trabalho e energia.
}

me deixaram memória significativa. Talvez por ter havido excesso de informalidade.

\subsection{Inauguração do ciclo avançado}

O primeiro teste operacional do ciclo avançado do CECM deu-se durante o primeiro semestre de 1993, quando os estudantes da primeira turma, então a ponto de completar o ciclo básico do CECM, se defrontaram com a escolha de orientador e definição, com ele, de programa de iniciação cientifica, bem como a definição do currículo complementar, servindo-se para isso de disciplinas oferecidas pelas diferentes unidades universitárias. Dificuldades surgidas nesse processo tiveram que ser aplainadas por nova Resolução CoG n⿳0 4005, decorrente de deliberação do CoG de 17-6-96 e baixada no dia seguinte pelo pró-reitor de graduação Celso de Rui Beisiegel. Ela determinava, em seu Artigo 1o, que

Os alunos do Curso Experimental de Ciências Moleculares (CECM), por solicitação da Comissão Coordenadora desse Curso, poderão matricular-se regularmente nas disciplinas de Graduação e de Pós-Graduação ministradas pelas Unidades Universitárias.

E, em seu Artigo $2^{\circ}$, que

Em havendo vagas, caberá à Comissão Coordenadora do CECM examinar, caso a caso, a questão de dispensa dos requisitos para a matrícula nas disciplinas pretendidas.

As dificuldades decorriam do conflito entre a flexibilidade conferida aos estudantes do CECM e as clivagens e barreiras tidas como 'naturais' no contexto do funcionamento corrente da universidade. De fato era tida como inviolável, por um lado, a classificação de disciplinas como pertencentes a duas categorias distintas, a de graduação e a de pósgraduação. Ocorreu porém, por exemplo, que estudantes da primeira turma que buscaram programas de iniciação científica no Instituto de Física, propusessem a inclusão da disciplina de pós-graduação de Mecânica Quântica como parte de seu currículo de graduação no ciclo avançado, em substituição às correspondentes disciplinas 'introdutórias' oferecidas aos estudantes de graduação do Instituto de Física. Essa substituição foi (e continua sendo) possível, 
dado o caráter também introdutório (e apenas tanto menos 'cauteloso' como mais completo) das disciplinas de pós graduação. Por outro lado, grande parte das propostas para o ciclo avançado envolviam violações do rol de prerrequisitos formais impostos como condição de matrícula, o que também teve que ser contornado.

\section{Transição, problemas e adaptações}

O processo sucessório na reitoria da USP foi marcado por uma inédita renúncia, a do reitor Roberto Lobo, no início do segundo semestre de 1993, e portanto um semestre antes do fim de seu mandato. Isso levou o vice-reitor Ruy Laurenti ao exercício da reitoria até a posse de Flávio Fava de Moraes, do Instituto de Ciências Biomédicas, como novo reitor, antecipada para o início de dezembro do mesmo ano.

Paralelamente a esse processo atípico de transição, os estudantes da primeira turma do CECM passaram à implementação pioneira de seus programas de iniciação científica, se espalhavam pelo campus da universidade para cursar as disciplinas que haviam sido propostas e aprovadas como complementação curricular correspondente ao ciclo avançado, oferecidas em diferentes unidades. Apesar do ineditismo do processo, a escolha de orientadores e a definição dos programas e complementações curriculares ocorreu sem maiores percalços. Os currículos personalizados aprovados envolviam, em muitos mas não todos os casos, reorientações importantes relativamente à opção original dos estudantes por ocasião do vestibular. A transição dos estudantes do ambiente especial do ciclo básico do CECM para atividades no contexto de eventualmente até mais de uma das unidades regulares da universidade também de deu sem maiores problemas.

O mesmo não pode ser dito do funcionamento do ciclo básico, uma vez concluído o processo seletivo para a terceira turma do CECM. Esse processo seletivo contou com um número de inscritos inferior aos dois anteriores (pouco mais da metade). Dos dez aprovados, apenas seis efetivamente se transferiram para o CECM. O oferecimento das disciplinas do ciclo básico continuava sendo frequentemente perturbado pela dificuldade de assegurar a colaboração das diferentes unidades envolvidas no curso em contabilizar a carga didática de seus docentes junto ao CECM, mau grado a existência da portaria da pró-reitoria de graduação a esse respeito (v. pag. 10).
Além disso, o conteúdo sobretudo de disciplinas de biologia e química sofria com interpretações divergentes de programas tipicamente pouco específicos. Apesar de ser experimental até na sua denominação, o controle dos resultados e questões surgidas na implementação do ciclo básico do CECM era insuficiente ou ineficaz, os problemas mais agudos sendo tratados de forma ad hoc.

\subsection{Duas novas administrações}

No início do ano de 1994, já então no início do mandato de Fava de Moraes na reitoria da universidade, deu-se a vacância do cargo de Coordenador do CECM devido a pedido nesse sentido do seu primeiro Coordenador, Hernan Chaimovich Guralnik. É desse período a comunicação da assessoria da pró-reitoria de graduação reproduzida na fig. 2, Atendendo a convite do novo pró-reitor de graduação, Carlos Alberto Barbosa Dantas, do Instituto de Matemática e Estatística, a coordenação foi assumida interinamente no mês de março por Jorge Lacerda de Lyra, que já havia contribuído com a implementação e ministração da disciplina instrumental de Computação e que nesse momento dedicava esforço considerável à sua participação na gestão de informática na universidade sob a liderança de Imre Simon, do Instituto de Matemática e Estatística. Esse fato foi comunicado aos estudantes do CECM em 15 de março, e oficializado com publicação da designação no Diário Oficial.

Nas próprias palavras do novo Coordenador, seu objetivo "era basicamente o de salvar o curso, e tentar impedir que ele acabasse sendo dissolvido. (...) Do ponto de vista acadêmico-administrativo houve aquela mudança do regime quadrimestral para o regime semestral usual da USP, sem a qual seria muito difícil alocar professores para o curso. Houve também uma reforma de [todas as disciplinas do ciclo básico], com subcomissões atuando em cada uma das áreas, que foi feita e até aprovada pelo Co. Houve ação de minha parte tanto no sentido de dar forma a uma nova comissão de coordenação quanto de obter docentes. Para a reforma do currículo foi preciso organizar subcomissões por área, uma para cada Instituto participante. Houve também o início da participação do IAG como instituto-membro do curso". Além disso, havia ainda "as coisas de infraestrutura. Aqui vão algumas: a montagem de uma infraestrutura de informática para o curso, a ligação do curso à rede da USP. Isto envolveu im- 
portações, através do CCE, que demoraram quase um ano. $\mathrm{O}$ conserto da infraestrutura elétrica, que estava toda em um estado de completo caos, com ligações improvisadas com outros prédios, incluindo até riscos sérios de incêndio. Houve também muitas negociações e conversas sobre uma mudança do curso para outros lugares. No fim, acabou sendo feita apenas uma reforma geral das instalações existentes. Já havia no curso uma sala de computadores do projeto Pró-Aluno do CCE, que foi reformada, e que eventualmente deu origem à adoção geral de Linux pelo Pró-Aluno." [10]

O processo seletivo para a quarta turma do CECM foi realizado também durante esse período. Esse processo era anunciado por um esquema de divulgação através de cartazes e panfletos distribuídos pela universidade. O número de inscritos foi ainda menor que no ano anterior, tendo finalmente se apresentado para a prova de seleção apenas 30 estudantes. Foi nessa ocasião, no entanto, que pela primeira vez foi adotado para a seleção o objetivo de preencher completamente as 25 vagas existentes para o curso, mesmo se isso implicasse no afrouxamento de critérios usados anteriormente. Dos 25 estudantes selecionados, 22 efetivamente se matricularam no CECM.

\subsection{Aprovação oficial e avaliação externa}

A pró-reitoria de graduação, por seu lado, providenciava a aprovação do Regulamento do CECM pelo conselho universitário. Isso permitiu, em particular, a extensão do processo de reconhecimento do curso para as instâncias exteriores à universidade, permitindo o registro nacional de diplomas.

Um fato adicional de importância crucial para o curso foi que, ao aprová-lo, o conselho universitário determinou ao reitor que constituísse uma comissão externa para avaliá-lo. Essa comissão foi formada pelo reitor Fava de Moraes com a missão de apresentar um 'relatório de mérito' sobre o CECM. Ela se reuniu para isso em 10 de janeiro de 1995. Foram seus membros relatores

- Antonio Cecceli de Matos Paiva Professor Titular da Escola Paulista de Medicina;

- Carlos Henrique de Brito Cruz Professor Titular do Instituto de Física da UNICAMP e atual PróReitor de Pesquisa;
- Jacob Palis Junior - Professor Titular do Instituto de Matemática Pura e Aplicada do CNPq;

- José Antunes Rodrigues - Professor titular da Faculdade de Medicina de Ribeiraão Preto;

- Cristiane Lopes - representante discente do CECM

No início do relatório de mérito a Comissão apresenta seu programa de trabalho:

(...) Após a exposição inicial do Prof. Dr. Carlos Alberto Barbosa Dantas, PróReitor de Graduação da USP, que se retirou da reunião, os membros da Comissão decidiram proceder da seguinte forma: a) fazer uma discussão inicial, baseada nas informações encaminhadas previamente a todos os membros, b) entrevistar os Coordenadores do Curso (Prof. Dr. Jorge L. de Lyra, coordenador atual; e Prof. Dr. Hernan Chaimovich, coordenador anterior) e, c) entrevistar a Srta. Cristiane Lopes representante do corpo discente.

A seção 9 do relatório de mérito enumera as recomendações da comissão relacionadas com problemas detetados no curso:

\section{PRINCIPAis PROBlemas E PERSPEC-} TIVAS

$(\ldots)^{5}$

1. O principal problema enfrentado atualmente pelo curso é a falta de engajamento do Poder Central, Institutos e demais Unidades envolvidas. A USP deve encampá-lo!

2. Os membros da Comissão Coordenadora devem ser indicados pelos diretores dos Institutos envolvidos e não pela Pró-Reitoria como ocorre presentemente.

3. O Coordenador do Curso deve ser indicado pelos membros da C.C. e ter um 'status' de Presidente de Comissão de Graduação, com amplos poderes e autonomia para executar

\footnotetext{
${ }^{5} \mathrm{~A}$ íntegra do relatório de mérito é reproduzida no material suplementar.
} 
o gerenciamento do curso. (...) O Coordenador deve ter uma posição (cargo ou função) reconhecida (e respeitada) pelos órgãos centrais da USP, Institutos e Departamentos.

4. Os Institutos e Departamentos devem estar comprometidos com o Curso e devem ceder de forma regular os professores para colaborarem com a execução do programa.

5. O Curso deve ter orçamento e estrutura administrativa própria. $\mathrm{O}$ Coordenador não pode ficar na dependência de outras estruturas universitárias. (... ) Seu orçamento não deve ser parte do orçamento da PróReitoria de Graduação. O orçamento é para atividades próprias, específicas, do curso: custeio, despesas com a realização de Palestras, Simpósios, Seminários e outros eventos científicos, com a finalidade de dar maior visibilidade ao curso.

Em conclusão a comissão afirma que

1. Baseados nos dados apresentados, desempenho dos alunos e discussão com os coordenadores do curso, a Comissão é de parecer que o curso mostra muita potencialidade desde que sejam vencidas as dificuldades apontadas acima.

2. Potencialmente deve constituir em excelente fonte de alunos muito bem preparados para a pós-graduação e as atividades científicas envolvidas na carreira do pesquisador.

3. Tem condições de servir de modelo para experimentos mais generalizados, relacionados ao ensino de graduação, estimulando a formação básica mais abrangente em ciências, sem perda da profundidade.

4. Na avaliação da Comissão este curso pode servir de exemplo para que se realize experimentos em outras áreas do conhecimento. O seu sucesso deve alavancar outras iniciativas dentro da USP, no sentido da modernização de programas de graduação em áreas menos tradicionais.

O testemunho do coordenador Jorge Lyra relativo à própria entrevista pela comissão avaliadora expõe uma perspectiva importante sobre o trabalho da comissão. Mais uma vez em suas próprias palavras, "a impressão que esta entrevista deixou em mim foi a de que, partindo de uma posição inicial extremamente cética e permeada de muitas dúvidas, e depois de muita análise e discussão, esta comissão finalmente se convenceu da importância e do potencial para o futuro da experiência representada pelo curso, e desenvolveu um julgamento muito positivo a respeito dele." 10

\subsection{Um novo formato para a coordenação}

Depois de permanecer vários meses "em estado demissionário" de sua interinidade como coordenador do CECM, Jorge Lyra apresentou à pró-reitoria de graduação a sua demissão irretratável no início de abril de 1995. No dia 20 desse mesmo mês o próreitor Carlos Alberto Dantas baixou a Portaria PRG 004/95 designando o que seria depois chamado de Comissão Diretora em substituição ao coordenador do curso:

O Pró-Reitor de Graduação da Universidade de São Paulo, no uso de suas atribuições legais, designa, os Professores Doutores ANTONIO FERNANDO RIBEIRO DE TOLEDO PIZA (IF), JOSÉ ATÍLIO VANIN (IQ), HENRIQUE VON DREIFUS (IME) e REGINA PEKELMANN MARKUS (ICB), para comporem a Direção do Curso Experimental de Ciências Moleculares, à qual(sic) indicará entre seus membros o Coordenador e as funções a serem executadas pelos demais membros.

O formato de uma comissão diretora que escolheria o coordenador entre seus membros é evidentemente estranho à estrutura administrativa do curso tal como descrita no Regulamento então vigente. Uma alteração do Regulamento envolve, porém, aprovações pelo conselho de graduação da universidade e também pelo Conselho Diretor, colegiado máximo do próprio CECM. Além disso, uma alteração das disposições do Regulamento referentes 
à coordenação do CECM devia, naquele particular momento, considerar também as recomendações do relatório de mérito apresentado pela comissão externa de avaliação, especialmente pelo fato de que uma delas era referente ao método de escolha e 'status' do coordenador do CECM. Como, no entanto, o pedido irretratável de demissão do coordenador exigia uma ação imediata por parte da pró-reitoria de graduação para garantir a continuidade do funcionamento do curso, a solução adotada foi a implementação imediata, embora sem amparo regulamentar, da comissão diretora.

A instalação efetiva da comissão diretora ocorreu na realidade em data anterior à da portaria que tratava de sua designação. Ela foi então, nesse sentido, informal, além de não regulamentar. A sua primeira reunião ocorreu ainda na primeira metade do mês de abril de 1995, e o primeiro retorno formal à próreitoria de graduação se deu através de um ofício datado de 25 de abril 6 Uma das questões levantadas nele como pedindo providências urgentes foi a de que "o curso possa indicar um representante oficial junto ao conselho de graduação com status equivalente ao de presidente de Comissão de Ensino de Graduação de unidade", "afim de que o curso adquira o status institucional necessário para o desenvolvimento de suas atividades no âmbito e em consonância com as atividades de Universidade relacionadas com ensino de graduação." Vale notar que tal observação foi apresentada independentemente das recomendações do relatório de mérito, cujo conteúdo não era à época do conhecimento da comissão diretora 7 . O

\footnotetext{
${ }^{6} \mathrm{~A}$ íntegra desse ofício é reproduzida no material suplementar, bem como contribuições de dois membros da comissão diretora redigidas para sua preparação. Ambas as contribuições são datadas de 17 de abril, data essa necessariamente posterior à primeira reunião da nova comissão.

${ }^{7}$ Um exemplo do que sói ser produzido na universidade frente a sugestões como a feita no terceiro ponto do relatório de mérito, quando devidamente submetidas às suas entranhas administrativas, pode ser visto no parecer do relator da Comissão de Legislação e Recursos do Conselho Universitário a Fls. 14 do Processo 97.1.11745.1.9 sobre a representação junto ao CoG do coordenador do Curso Experimental de Ciências Moleculares. O seu voto tem como consideranda iniciais: 1. Este relator é entusiasta do Curso de Ciências Moleculares, pois, vê nele um embrião do "college" que deveria ter sido adotado genericamente pela USP como um sistema superior de ensino de graduação. 2. Ademais, este relator também reconhece nos membros da Comissão de Avaliação pessoas do mais alto gabarito científico. Não obstante, entende que a frase inserida no relatório pedindo mais atenção ao curso de Ciências Moleculares tem valor simbólico, pois, as pessoas dessa comissão seriam as últimas a defender "representação
}

ofício trata ainda do processo seletivo a ser levado a cabo para a quinta turma do CECM, com propostas visando o aumento do número de candidatos para o curso. No último parágrafo, reiterando sua disposição em trabalhar pelo CECM, a comissão diretora "propõe a seguinte divisão de atribuições entre seus membros:

\section{Coordenador Administrativo: Atílio Va- $\operatorname{nin}$ \\ Coordenadora Discente: Regina P. Mar- kus \\ Coordenador Docente: Henrique von Drei- fus \\ Coordenador geral: A. F. R. de Toledo Piza"}

A atribuição que me coube foi decidida na primeira reunião da comissão, à qual não pude comparecer.

A discussão de uma eventual mudança no Regulamento do curso pelo conselho de graduação da universidade se iniciou, portanto, com a comissão diretora já instalada e em operação, tendo ela sido, além disso, incluída no circuito de tramitação dessa mudança. A falta de amparo regulamentar foi contornada pela pró-reitoria, no âmbito do conselho de graduação, caracterizando a designação da nova comissão como tendo sido feita "em caráter experimental", sendo que "de acordo com os resultados que fossem observados, seria modificado o Regulamento do curso". Essa foi, de fato, a argumentação apresentada pelo pró-reitor de graduação em reunião de 22 de junho de 1995 do conselho de graduação. Nessa reunião, após tratar da recomendação da seção 9 do relatório de mérito referente à comissão coordenadora do CECM, o conselho de graduação 'considerou', quanto à questão da indicação do coordenador do curso, "que se deve apoiar a proposta da PróReitoria de Graduação cujo teor é o seguinte:
'A Coordenação do Curso será exercida por uma comissão composta de quatro professores, designados pelo Pró-Reitor de Graduação, ouvido o Conselho Di- retor. O Coordenador Geral do Curso, membro da referida comissão, será esco- lhido por seus pares'."

política em colegiados”. (...) O voto do relator é contrário à proposta de representação, "salvo melhor juízo". A íntegra do parecer, datado de 16 de maio de 1997, é reproduzida no material suplementar. 
Um documento 'resumindo a proposta de modificação do regulamento' do CECM foi aprovado em reunião de 17 de agosto. Em 14 de setembro o processo referente à mudança de regulamento foi encaminhado pelo pró-reitor de graduação ao coordenador geral do CECM com o despacho

Tendo sido aprovado pelo Conselho de Graduação, em sessão de 17.8.95, o documento de fls. 312/313, estamos encaminhando o presente processo a V. Sa. esclarecendo que a matéria será submetida ao Conselho Diretor do CECM.

Posteriormente o assunto será levado ao CoG.

O documento citado no despacho é o que contém a proposta da pró-reitoria de graduação transcrita acima, referente à coordenação do CECM. O mesmo processo continha também (fls.299/308) o relatório de mérito da comissão externa de avaliação, o que levou a comissão diretora a apontar o paralelismo entre a recomendação do relatório de mérito referente ao status do coordenador no quadro da universidade e as suas próprias considerações levadas à pró reitoria de graduação em no ofício de 25 de abril, manifestando finalmente que

"A atual comissão diretora do curso entende que deve, evidentemente, abster-se de qualquer manifestação sobre a proposta da Pró-Reitoria de Graduação constante do documento de fls. $312 / 313$ do presente processo bem como das questões correlatas ali tratadas, dado que tal proposta e tais questões colocam em questão sua própria existência e constituição. Acredita, no entanto, que deve encarecer aos colegiados superiores a inadiabilidade de decisões que contemplem de forma explícita e definitiva uma inserção eficaz do CECM nas estruturas administrativas e acadêmicas da Universidade, qualquer que seja a decisão final acerca de tais outros assuntos."

O Conselho Diretor do CECM reuniu-se para o que consta como sendo a sua sétima sessão em 31 de outubro de 1995. Um dos itens da pauta tratava da alteração do Regulamento proposta pela próreitoria de graduação. Uma pauta suplementar para essa sessão inclui como único item a "Apreciação do relatório do Coordenador Geral correspondente ao período de maio a outubro de 1995", embora o título do relatório apresentado o caracterize como sendo "da Comissão Diretora". A aprovação da alteração do Regulamento e a aceitação do relatório não chegaram ainda, porém, a completar os requisitos para devolver ao CECM a qualidade de ser regulamentar. Isso só se deu na realidade com a aprovação da mudança de Regulamento pelo conselho de graduação da universidade em sessão de 14 de dezembro de 1995, finalmente publicada como Resolução CoG 4230/96 em 4 de janeiro de 1996.

\section{O CECM e a comissão diretora em 1995}

Como já foi dito, a comissão diretora foi efetivamente instalada pouco antes de sua designação oficial pela portaria de 20 de abril de 1995, adotando imediatamente uma rotina de reuniões semanais, realizadas às quartas-feiras a partir das $11 \mathrm{~h} 30 \mathrm{~m}$, sempre nas instalações do curso. Duas questões a exigir providências práticas imediatas foram a necessidade de medidas urgentes para viabilizar o processo de seleção da quinta turma e a necessidade de definir, com as diferentes unidades participantes, a alocação de docentes para ministrar as disciplinas do ciclo básico durante o segundo semestre de 1995, o que que não havia sido considerado até então.

Além disso, no entanto, havia muitas outras dificuldades, e de várias ordens. Em primeiro lugar, era evidente a existência de uma série de problemas e instabilidades no relacionamento com o curso da turma ingressada no ano anterior. Parte dos problemas envolviam responsabilidades do próprio curso que não tinham podido ser atendidas, como uma das disciplinas previstas (Biologia) não estar sendo ministrada. Outro problema era o elevado grau de absenteísmo em algumas das disciplinas oferecidas, levando a um desempenho extremamente heterogêneo dos estudantes. Em segundo lugar, eram patentes dificuldades com os programas de algumas disciplinas (especialmente Biologia e Química), agravadas pelas complicações decorrentes da não ministração no semestre letivo em curso. Finalmente, havia problemas sérios de infraestrutura, devido à não implementação do reequipamento previsto para suceder a reforma levada a efeito no favo 22: por exemplo, a secretaria do curso não dispunha de um 
terminal ligado ao arquivo de dados da universidade relativo ao corpo discente, e não dispunha de qualquer tipo de copiadora, tendo que recorrer sempre que necessário a facilidades disponíveis apenas nas dependências da pró-reitoria de graduação, em outro edifício do campus.

\subsection{A primeira formatura e a seleção da quinta turma}

Apesar da 'divisão de atribuições' comunicada à pró-reitoria de graduação em resposta à disposição nesse sentido da portaria de designação, a comissão diretora decidiu internamente trabalhar de forma 'a priori' simétrica, beneficiando-se contudo, sempre que possível, das possibilidades diferenciais de cada um de seus quatro membros. Dessa forma, uma contribuição importante para a formatação final do processo de seleção para a quinta turma do CECM partiu de Atílio Vanin, que se valeu para isso também de sua experiência como diretor da FUVEST. Havia, segundo o seu ponto de vista, a necessidade de aumentar a demanda pelo curso, com o propósito de permitir uma seleção mais eficiente, "o ideal sendo pelo menos 10 candidatos por vaga". Para isso sugeriu o envio pela pró-reitoria, com colaboração da FUVEST, de mala direta aos alunos melhor classificados no vestibular 95, convidando-os para um evento de divulgação, realizado dentro do prazo de inscrições, e para a inscrição na seleção. Em 1995 o calendário relativo ao processo de seleção foi

\section{9/5 a 23/6 - Recebimento de inscrições. \\ $12 / 6$ - Evento de divulgação. \\ 1으 - Prova escrita. \\ $6 / 7$ e $7 / 7$ - Entrevista.}

Nesse ano o evento de divulgação consistiu em uma reunião solene realizada na sala do conselho universitário da USP, na qual teve lugar a cerimônia de colação de grau da primeira turma do CECM. Devese notar que isso ocorreu antes do reconhecimento do curso pelas instâncias externas à USP, e portanto sem emissão de diplomas oficiais. Essa cerimônia foi seguida de um coquetel para os convidados, com a presença de professores e outras pessoas ligadas ao curso. O número de inscrições chegou a 100, dos quais 51 estudantes compareceram à prova escrita. Desses foram finalmente selecionados 20 , dos quais 19 efetivamente se matricularam no curso.
Foram dez os formandos da primeira turma do CECM. Dois dentre eles deixaram a USP para o prosseguimento de seu trabalho em nível pós-graduado, em instituição nacional em um dos casos (Instituto Nacional de Pesquisas Espaciais), e no outro caso fora do país (Brown University, EUA). Em nenhum desses dois casos o não reconhecimento do curso pelas instâncias externas à USP constituiu qualquer problems?

\subsection{Avaliação dos alunos do ciclo básico}

O momento mais crítico na condução do CECM em 1995 ocorreu por ocasião de uma reunião conjunta da comissão diretora com a comissão coordenadora do curso com o objetivo de proceder à avaliação da terceira e da quarta turma, ingressadas respectivamente em 1993 e em 1994. Essa reunião ocorreu em 4 de julho, em meio aos processo de seleção para a quinta turma. O desempenho de um dos seis estudantes da terceira turma foi considerado insuficiente em três das quatro disciplinas cursadas, tendo por isso a comissão coordenadora optado pela sua exclusão. O caso da quarta turma tinha no entanto contornos especiais. De fato, a disciplina de Biologia não fora ministrada, e a disciplina de Química, em consequência de incidentes de natureza disciplinar ocorridos em um laboratório do Instituto de Química, teve seu oferecimento interrompido apesar do esforço empregado no sentido de evitar tal desfecho. Procurando manter as características e os objetivos do CECM tendo em conta, ao mesmo tempo, a existência dessas anomalias, a comissão coordenadora decidiu basear a avaliação dos alunos da quarta turma nas três disciplinas restantes (Computação, Matemática e Física), apenas. A deliberação foi longa e penosa, e levou à decisão de desligar do curso dez dos quatorze estudantes. Essa decisão foi baseada, por um lado, no desempenho claramente diferenciado positivamente de quatro estudantes e no desempenho claramente insatisfatório de oito dos outros estudantes (que, em particular, não haviam se submetido à avaliação prevista na disciplina de Matemática). Um exame mais deta-

\footnotetext{
${ }^{8}$ Por outro lado, bem mais tarde, após retornar de um programa de doutoramento em física concluído o exterior, um estudante da segunda turma do CECM teve sua inscrição em concurso docente para a área de física não homologada em uma universidade federal brasileira por ter apresentado um diploma de graduação, já devidamente registrado, em Ciências Moleculares, e não em física.
} 
lhado do desempenho dos dois outros alunos levou também à opção pelo seu desligamento. Um desses dois alunos recorreu dessa decisão, e tendo o recurso sido indeferido pela comissão diretora, foi por solicitação do interessado elevado à consideração do Conselho Diretor.

A exigir atenção especial havia também, por certo, a recorrência de problemas sérios com a ministração das disciplinas de Biologia para o ciclo básico do CECM. Além do caráter crônico da dificuldade em assegurar a designação de docentes para essas disciplinas em particular, ocorriam grandes flutuações quanto aos programas efetivamente desenvolvidos quando as disciplinas eram ministradas.

Nesse contexto, deve ser lembrado que a estrutura curricular proposta para o ciclo básico por ocasião do estabelecimento inicial do curso incluiu diversos elementos de algum exotismo, não apenas no que se refere a programas, mas também ao próprio elenco de disciplinas. Quanto aos programas propostos, e usando uma frase do primeiro relatório da comissão diretora, não deve estar longe da verdade a afirmação de que nenhum deles tenha chegado a ser efetivamente ministrado sequer uma só vez. As razões para isso iam desde inviabilidade prática dos programas propostos até problemas ligados à disponibilidade de docentes ou de equipamento, no caso da disciplina instrumental Computação. Quanto aos programas, nas disciplinas de Matemática e Física, a existência de um conteúdo básico padrão, de adoção essencialmente universal, atendendo ao espectro de interesses tanto de ciências exatas como de ciências biológicas, disponível em textos de alta qualidade pode funcionar como um atrator suficientemente forte para limitar instabilidades. Isso de fato ocorreu na reformulação dos programas levada a efeito sob a coordenação de Jorge de Lyra. Apesar de incluída nesse mesmo processo de reformulação de programa, a disciplina de Biologia para a quarta turma do curso sequer foi ministrada durante o primeiro semestre de 1995. Deve ser lembrado ainda que, nesse mesmo semestre, a disciplina de Química para essa mesma turma foi interrompida por incidente de natureza disciplinar em aulas de laboratório nas dependências do Instituto de Química. Essas questões tiveram que ser tratadas em reuniões de um dos membros da comissão diretora (Regina P. Markus) respectivamente com instâncias do Instituto de Ciências Biomédicas, do Instituto de Biociências e do Instituto de Química. Em particular, os pro- gramas das quatro disciplinas de Biologia do ciclo básico foram reformulados com o objetivo de definir um conteúdo básico para essa área, e acertadas medidas para evitar a recorrência de problemas quanto à designação de docentes dessas unidades para as disciplinas do ciclo básico do CECM.

A ideia de que o programa de tutoria, que fazia parte da formulação inicial do CECM por seus idealizadores, poderia, se mantido em pleno funcionamento, contribuir de forma importante para evitar ou pelo menos limitar instabilidades como as que ocorreram com a quarta turma, levou a comissão diretora a promover sua reativação por ocasião do ingresso da quinta turma no ciclo básico. Como benefício adicional era também esperado que a comissão coordenadora pudesse contar com um conjunto maior de informações no processo de avaliação dos estudantes. Para isso o novo grupo de tutores foi constituído de forma a excluir explicitamente membros das comissões coordenadora e diretora do CECM. Da mesma forma que a partir do início do funcionamento do CECM, o programa de tutoria reativado entrou imediatamente em declínio, sendo enfim finalmente eliminado.

\subsection{A sétima reunião do Conselho Diretor}

Em 31 de outubro de 1995 deu-se a sétima reunião do Conselho Diretor de CECM. Estiveram presentes à reunião os pró-reitores de graduação, Carlos Alberto Dantas (presidente nato do Conselho) e de Pesquisa, Hugo Armelin, o diretor científico da FAPESP José Fernando Perez, o diretor do Instituto de Biociências João Stenghel Morgante, a vice-diretora do Instituto de Ciências Biomédicas Regina Scivoletto, o vice-diretor do Instituto de Física Henrique Fleming, o diretor do Instituto de Química Walter Colli e a representante discente Carla Vital Otero. Os quatro membros da comissão diretora participaram da reunião como convidados. Após tomar conhecimento do relatório da comissão diretora e do Relatório de Mérito da comissão externa de avaliação, a alteração do regulamento do CECM substituindo o coordenador pela comissão diretora (presente como convidada) foi aprovada. Foi também apreciado o recurso interposto por um dos estudantes da quarta turma que fora desligado do CECM pela comissão diretora, sendo ratificada a decisão dessa comissão.

A ata dessa sétima reunião do Conselho diretor registra, com alguns pormenores de praxe, todos 
esses pontos, dos quais se pode dizer que não trazem maiores surpresas. Parece-me apropriado, no entanto, registrar uma intervenção da vice-diretora do Instituto de Ciências Biomédicas, Regina Scivoletto, ocorrida provavelmente durante a discussão de um dos dois relatórios (relatório de mérito da comissão externa de avaliação e relatório da comissão diretora 'experimental') que foram apreciados na ocasião. Ela se referia à possível relevância da experiência em curso no CECM para a universidade como um todo, e não foi registrada pela ata da reunião. Tenho dela no entanto memória viva: consistia na observação de que havia um aspecto do CECM que poderia ser estendido imediatamente a toda a universidade, que consistia na flexibilidade adotada para o ciclo avançado. Embora tampouco tenha tido qualquer consequência posterior, essa observação indica claramente como os meandros de um processo experimental (no caso, o CECM) podem sugerir alterações criativas também fora do âmbito imediato em que tenha sido ou esteja sendo conduzido.

\section{Estabilização do CECM e a queda do ' $\mathrm{E}$ '}

A aprovação da proposta de uma comissão diretora pelo Conselho diretor do CECM regularizou o que se pode chamar a situação do curso frente às suas instâncias internas. A alteração do Regulamento do curso foi em seguida aprovada pelo conselho de graduação da universidade na sessão de 14 de dezembro de 1995, e publicada como Resolução CoG 4230/96 em 5 de janeiro do ano seguinte. Essa alteração não foi contudo apreciada pelo conselho estadual de educação, que recebeu pedido de reconhecimento do CECM que havia sido formulado ainda em 1994, com base no Regulamento anterior, o qual havia sido aprovado pelo conselho universitário, em outubro de 1994. Esse pedido de reconhecimento foi aprovado pelo conselho estadual de educação em 27 de março de 1996, e foi com base no parecer referente a esse reconhecimento que o então ministro da educação, Paulo Renato de Souza baixou portaria, em 13 de junho, reconhecendo o "curso de Ciências Moleculares, ministrado pela Universidade de São Paulo-USP". Parece ter sido essa a primeira referência ao CECM que omite, provavelmente em virtude de um lapso, o qualificativo "experimental". A partir desse último reconhecimento, porém, o CECM passou a ser referido no âmbito da universidade como CCM apenas, embora seu regulamento, já devidamente atualizado, o identificasse ainda explicitamente como "experimental". A oficialização regulamentar da nova denominação se daria apenas na seguinte e bastante mais tardia modificação de regulamento, ocorrida doze anos depois, em 2008.

A estabilidade do regulamento, modificado pela substituição do coordenador pela comissão diretora de quatro membros, refletiu uma correspondente regularidade no funcionamento do curso durante o período de cerca de doze anos posterior a esse reconhecimento do curso pelo Ministério de Educação. Substituições e mudanças de atribuições ocorreram essencialmente dentro das regras estabelecidas. $\mathrm{Na}$ comissão diretora, a primeira substituição foi a de Henrique von Dreifus por Saulo Maciel de Barros, ambos do Departamento de Matemática e Estatística, em setembro de 1996. Essa substituição foi implementada pela pró-reitoria de graduação e posteriormente homologada em uma nova reunião (a oitava) do conselho diretor, realizada em 21 de outubro de 1997. Esta homologação vem de encontro à disposição pela qual os membros da comissão coordenadora devem ser indicados pelo conselho diretor. Uma pequena quebra do regulamento ocorreu, no entanto, ao ser de dois anos o intervalo de tempo entre a sétima e a oitava reuniões do conselho diretor, já que a determinação do regulamento é a de que esse conselho se reúna ordinariamente com periodicidade anual. Este hiato pode ser atribuído pelo menos em parte à dificuldade de reunir esse colegiado, face ao peso atribuído à tarefa de supervisionar o CECM relativamente aos demais encargos de diretores de unidades universitárias e de instituições de fomento. Ele se agravou em anos posteriores, e levou finalmente a uma nova revisão do regulamento do curso, completada em 2008, que eliminou o conselho diretor (bem como, agora então oficialmente, o ' $E$ ' de CECM).

Para a oitava reunião do conselho diretor foi convidada a apresentar um relato sobre o curso a nova coordenadora geral, Regina P. Markus, indicada pela comissão diretora para essa função em março de 1997, após a sua transferência para o Instituto de Biociências como professora titular por virtude de concurso ali realizado. A apresentação se deu durante o expediente da sessão. A ordem do dia incluiu, além de alguns poucos itens de caráter rotineiro (incluindo a substituição havida na comissão 
diretora), discussões sobre as instalações do curso e sobre a avaliação do ciclo avançado. No que se referia às instalações do CCM no favo 22 das Colmeias, a questão existente consistia em algumas deficiências relevantes, como a ausência de instalações sanitárias internas combinada com o fato de que as externas mais próximas haviam sido isoladas por um muro de sólida alvenaria erguido para isolar as dependências do Instituto de Estudos Brasileiros (IEB), alojado em favos adjacentes. Isso foi efetivamente levado a cabo nos anos subsequentes, em seguida a uma reforma empreendida pela universidade nas guaritas à entrada de estacionamentos no campus que as dotava, em particular, de instalações sanitárias. $\mathrm{A}$ reivindicação do $\mathrm{CCM}$ junto à pró-reitoria de graduação chegou a ser formulada (informalmente) dizendo "precisamos de uma das novas guaritas no favo 22 !".

A avaliação dos alunos do ciclo avançado do CCM, levada a efeito pela comissão coordenadora do curso, evoluiu em pouco tempo para uma padronização de procedimentos e critérios usados regularmente. Além dos resultados obtidos nas disciplinas cursadas em diferentes unidades da universidade, tais como registrados oficialmente, a avaliação considerava ainda o desenvolvimento do trabalho referente ao programa de iniciação à pesquisa. Um dos elementos para isso consistia em um relatório de avaliação fornecido semestralmente pelos orientadores, no qual deviam ser abordadas também quaisquer dificuldades de implementação ou propostas de alteração do currículo aprovado para o aluno. Como elemento adicional para julgar o desenvolvimento do trabalho de iniciação científica, o curso passou a promover, ao fim de cada semestre letivo, sessões abertas de exposição de trabalhos pelos alunos do ciclo avançado, geralmente em forma de painéis, durante as quais os membros da comissão coordenadora tinham oportunidade de colher mais elementos para a avaliação, discutindo com os próprios alunos os respectivos trabalhos. Em várias ocasiões, um eco dessa apresentação de painéis era montado por ocasião dos eventos anuais de divulgação do CCM para a seleção de uma nova turma, como exemplos, para os eventuais interessados, do espírito e de resultados do curso.

O novo mandato reitoral Jaques Marcovitch, iniciado ainda em fins de 1997, trouxe para a pró-reitoria de graduação Ada Pelegrini Grinover, professora da Faculdade de Direito. Sua gestão foi extrema- mente positiva com relação à operação e ao aperfeiçoamento operacional do CCM. O tratamento dado a problemas surgidos na operação do curso, quando levados à sua consideração, tipicamente não se limitou a medidas apenas tópicas, 'ad hoc', mas alterações globais capazes de beneficiar toda a universidade. Um exemplo disso foi a dificuldade, agora de natureza burocrática, de fazer constar no histórico de graduação de estudantes do CCM eventuais disciplinas de pós graduação cursadas durante o ciclo avançado. A componente 'local ao CCM' da solução consistiu na criação de novas disciplinas denominadas Complementos, com conteúdo vazio, a ser preenchido em cada caso pelo da disciplina de pós graduação cursada, o que as tornava a informação palatável ao gosto dos sistemas da universidade. Paralela e conjuntamente com isso, no entanto, foi instituída na universidade a possibilidade geral de usar disciplinas de pós-graduação em currículos de graduação, suprimindo de fato a segregação entre as duas classes de disciplinas. Medidas desse tipo constituem evidentemente uma das formas pelas quais a existência do CCM pode contribuir para uma maior abertura da universidade como um todo.

Outro tipo de radiação a partir do CCM para toda a universidade é o que emerge claramente, em estilo caracteristicamente seguro e incisivo, da entrevista de Ada Pellegrini Grinover concedida por ocasião do septuagésimo aniversário de universidade [11]. Diz nela a já então ex-pró-reitora sobre sua gestão:

O primeiro ano foi de planejamento: todo mundo achou lindo, todo mundo me convidava para expor os projetos, provavelmente com a ideia de que ficassem no papel.

O segundo ano foi de concretizações, e aí é que começou a luta. A FFLCH, por exemplo, ficou louca, porque eu queria criar um curso interdisciplinar de Humanidades nos moldes daquele que tinha sido criado para Ciências Moleculares. Sentiram-se ameaçados em seus cursos tradicionais. Fui chamada de "agente do FMI", "agente do Banco Mundial". Fui a um debate e os alunos quase me lincharam, teve aluno com o dedo em riste no meu nariz, pedindo satisfações políticas, dizendo que eu era elitista. Estudamos a criação de cursos sequenciais, porque nem todos podem ficar cinco 
anos na Faculdade para começar a trabalhar: muitos precisam de uma formação ótima, mais rápida, e esses cursos poderiam ser a solução. Foi outro escândalo. O curso de relações internacionais, juntando Ciência Política, História e Direito foi outra luta, não queriam saber.

No terceiro ano de gestão, apesar de tudo, começaram a me compreender. Mas não ousaram me eleger [para a reitoria da universidade].

Desde as primeiras turmas formadas em Ciências Moleculares (inclusive da primeira turma, anteriormente ao reconhecimento oficial do curso pelo conselho federal de educação) vários dentre os exalunos prosseguiram no seu trabalho procurando cursos de pós graduação no exterior. Um efeito curioso ocorreu com relação à Brown University, em Providence, R.I, nos Estados Unidos da América, para onde o bom desempenho dos primeiros admitidos estimulou tanto a procura como a aceitação de outros por parte da universidade. Em meados de 2003, tendo deixado a presidência do país, Fernando Henrique Cardoso iniciou um período de quatro anos como 'professor-at-large' na Brown University.

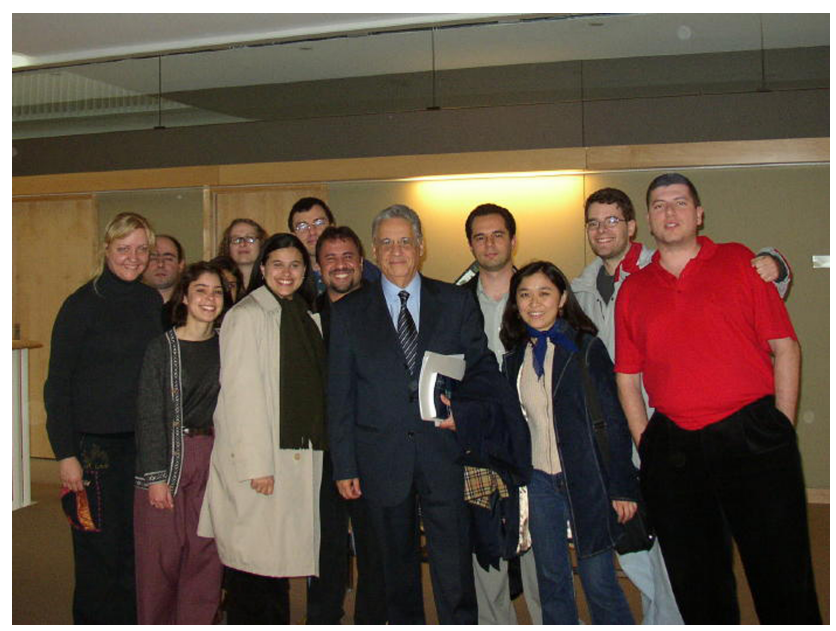

Figura 3: $\mathrm{O}$ ex-presidente Fernando Henrique Cardoso na Brown University, em 2003, rodeado de outros brasileiros. À sua esquerda, da esquerda para a direita na foto: Antonio Candido de Camargo Guimarães Jr. (segunda turma do CECM, recém doutorado em física), Yeung Luk Chong (quinta turma do CECM, estudante de pós graduação em física), Ben Schrag (recém doutorado em física) e Daniel Doro Ferrante (quarta turma do CCECM, estudante de pós graduação em física). À sua direita, estão, entre outros também brasileiros, estudantes do Department of Portuguese and Brazilian Studies.
Depois de uma de suas aulas durante o verão americano de 2003 foi tirada a foto mostrada na figura 3. na qual aparecem, à esquerda do ex-presidente, três ex-alunos do CECM, um já recém doutorado ali e dois outros ainda como estudantes de pós graduação.

Em 14 de maio de 2004 chegou às minhas mãos para assinatura o processo contendo mais uma recondução junto à comissão diretora do CCM. Notando que havia já estado nessa posição por cerca de nove anos, não me permiti aceitar a nova recondução.

\subsection{O Regulamento de 2008}

A mais recente reformulação do Regulamento do Curso de Ciências Moleculares resultou de deliberação do conselho de graduação da universidade na sessão de 19 de junho de 2008 e da comissão de legislação e recursos do conselho universitário em 12 de agosto do mesmo ano. Ela foi publicada como Resolução CoG no 5460 em 22 de agosto também do mesmo ano. Esta reformulação encerrou a uma crise administrativa de natureza exógena, alimentada em última instância pela inobservância das disposições do regulamento acerca das atribuições do conselho diretor. De fato, ela foi deflagrada em agosto de 2006 pela diretoria do instituto de física, ao questionar a sua não participação na constituição das comissões coordenadora e diretora de então e tomando, como consequência disso, a iniciativa de destituir os então representantes do instituto de física nessas instâncias e de indicar outros.

O novo regulamento de 2008 mantém intocada a definição original de objetivos do agora denominado oficial e simplesmente Curso de Ciências Moleculares. Quanto à estrutura administrativa, ele simplesmente elimina o conselho diretor, reduzindo a apenas duas as instâncias administrativas: a comissão diretora e a uma 'comissão de graduação', que consiste essencialmente numa renomeação da comissão coordenadora. Os membros da comissão diretora são agora cinco, representando respectivamente cada uma das unidades participantes (Institutos de Matemática e Estatística, Física, Química, Biologia e Ciências Biomédicas). A comissão de graduação conta com dois representantes de cada uma dessas unidades, além do coordenador do curso, escolhido pela comissão diretora dentre seus membros, 
e de representação discente. Seu presidente nato é o pró-reitor de graduação da universidade. Devido à exclusão do conselho diretor, a escolha dos membros da comissão diretora e da comissão de graduação passa a ser feita pelas congregações das respectivas unidades.

Outra alteração aperfeiçoa o artigo 18 da primeira versão do regulamento (v. pag. 8), que é substituído por algo próximo do que era de fato o procedimento adotado desde a instalação do primeira comissão diretora, em que pese a ambiguidade do condicionamento final:

Artigo 12 - Os professores que ministram disciplinas no CCM serão designados para tal fim pela Comissão Diretora, a partir das indicações de seus membros, ouvida a respectiva Unidade.

São também mantidas as disposições referentes ao computo, pelos departamentos das diferentes unidades, da carga horária de seus docentes junto ao CCM.

A mudança mais profunda introduzida pelo novo regulamento foi portanto substituir designações para as comissões administrativas do CCM feitas por um colegiado de diretores por designações feitas por um conjunto de congregações. Isso certamente contribui para reduzir as flutuações estatísticas que podem ser produzidas por possíveis personalismos em um contingente restrito de diretores. Por outro lado, implica em uma inércia aumentada para reorientações que se apresentem desejáveis. Regido por ele, o curso manteve o seu funcionamento normal nos últimos anos.

Um fato importante que deve por fim ser ressaltado é a realimentação do CCM, nos últimos anos, pela participação de ex-alunos em sua condução. Seu atual coordenador, Fábio Armando Tal, professor associado do Instituto de Matemática e Estatística, é ex-aluno da quinta turma do CCM. Renato Vicente, também professor associado do Instituto de Matemática e Estatística, ex-aluno da primeira turma do CCM, esteve encarregado de ministrar disciplinas de Matemática para o ciclo básico, e Fábio Rodrigues, professor doutor do Instituto de Química, ex-aluno da décima primeira turma do CCM, esteve encarregado de ministrar disciplinas de química para o ciclo básico.

\section{Algumas ideias finais}

O curso especial criado em 1991 na USP como Curso Experimental de Ciências Moleculares parece ter tido uma variedade de motivos e intenções na sua concepção e criação. No entanto, as trajetórias seguidas até mesmo pelos os alunos de sua primeira turma mostram já claramente que o resultado da criação tendeu rapidamente a se estabilizar como um curso multidisciplinar realmente polivalente, no sentido de aberto para todas as ciências matemáticas e da natureza, independentemente de seu grau de 'molecularidade'. Ao lado de estudantes que, no ciclo avançado se encaminharam para áreas distantes da opção feita por ocasião do exame vestibular, outros mantiveram a opção original. Estes, mesmo tendo mantido seu interesse em uma formação em um domínio contemplado pelas 'carreiras' tradicionalmente oferecidas pela universidade entre as opções do exame vestibular, tendo se transferido para o curso de ciências moleculares puderam se beneficiar muito da flexibilização de currículo e da abertura irrestrita para os oferecimentos de outras unidades, conseguindo no mesmo intervalo de tempo formação muito mais significativa $9^{9}$. Sendo, por outro lado, a (super?)valorização de denominações uma idiossincrasia até de natureza cultural bastante difundida, o curso manteve Ciências Moleculares em seu nome, que se viu porém efetivamente transformado em uma 'marca de fantasia' que, como tal, valorizou-se pelo que acabou por representar.

Mau grado a recomendação enfática da comissão externa que avaliou o CECM ao fim de seus primeiros anos de existência ("A USP deve encampá-lo!") o acoplamento com o organismo 'normal' da universidade manteve-se relativamente fraco, como indicado, por exemplo, pelo progressivo 'desligamento' do nível administrativo mais alto do curso, que foi o conselho diretor, bem como pelo fato de que até o presente a universidade está muito longe de se aproximar do expresso no ponto 3 . das recomendações do relatório de mérito da comissão externa de avaliação: o coordenador do CCM tem voz mas não voto no Conselho de Graduação. O acoplamento fraco pode, por um lado, ter complicado a solução de problemas, tendo mesmo criado alguns por conta própria, como o que levou à reformulação de 2008 do Regulamento. Por outro, contribuiu com um aumento de

\footnotetext{
${ }^{9}$ Cabe lembrar aqui a observação da vice diretora do Instituto de Ciências Biomédicas, Regina Scivoletto, durante a sétima reuni ao do conselho diretor do então CECM.
} 
liberdade de operação com relação a vínculos tradicionais, como os que preservam a identidade das diferentes unidades da federação universitária assegurando aos estudantes, além visibilidade, também a acessibilidade à totalidade de recursos existentes na universidade, sem ter que se haver com a inércia global da federação de unidades universitárias. O passo que consistiu na substituição da ideia inicial de um coordenador único para o CECM por um órgão coletivo abarcando as diferentes unidades (a comissão diretora) representou um passo adaptativo crucial para o funcionamento do curso, que funciona no favo 22 das Colmeias, enquanto imerso nessa federação.

\section{Agradecimentos}

Agradeço a Fábio Tal, atual coordenador do CCM, por me dar acesso a documentos e informações relativos ao curso que foram cruciais para a preparação deste escrito. Agradeço também aos funcionários da secretaria do CCM, Patrícia Pelleschi Taborda Rodrigues e Nelson Zanotti da Silva, que com eficiência e entusiasmo me auxiliaram na seleção e cópia dese material. Agradeço aos ex-alunos do CCM Gabriela Lima Lichtenstein, Antonio Cândido de Camargo Guimarães Jr. e Daniel Doro Ferrante por correspondência que me ajudou a reconstruir o contexto da fotografia reproduzida na fig. 3 . Um agradecimento especial é devido a meu colega Jorge de Lyra por me ter fornecido um rico relato acerca de sua prolongada interinidade na coordenação do CCM. Finalmente agradeço aos editores da RBEF pela provocação que me levou à presente empreitada.

\section{Referências}

[1] Shozo Motoyama (org.), USP 70 Anos - Imagens de uma História Vivida (EDUSP, São Paulo, 2006).

[2] Alexandre Marcos de Mattos Pires Ferreira, A Criação da Faculdade de Filosofia, Ciências e Letras da USP - Um Estudo sobre o Início da Formação de Pesquisadores e Professores de Matemática e de Física em São Paulo, disponível em http://www.sbhc.org.br/resources/anais/10/ 1344217546_ARQUIVO_TextoFinal-AlexandreM. M.P.Ferreira.pdf.

[3] Universidade de São Paulo, Estatuto, Art. 51 (2002).

[4] v. O Instituto, Histórico em http://www3.icb.usp. br/corpoeditorial/.

[5] v. Ref. [1], Entrevista de Erney F. Plessmann de Camargo, p. 550.
[6] ibid., p. 545.

[7] Entrevista - Profissão Cientista, Revista Diálogo Médico 16, 40 (1990).

[8] v. http://wiki.cecm.usp.br/index.php/Por_ que_moleculares\%3F (página criada por estudantes do curso mas com pouca atualização recente).

[9] Memória Roda Viva - Roberto Leal Lobo 2/12/1991, http://www. \rodaviva.fapesp.br/materia/ 464/entrevistados/roberto_leal_lobo_1991.

[10] Jorge L. de Lyra, comunicação particular.

[11] v. Ref. [1], Entrevista de Ada Pellegrini, Grinover, p. 440. 